\title{
Article \\ Prenatal Skeletal Muscle Transcriptome Analysis Reveals Novel MicroRNA-mRNA Networks Associated with Intrauterine Growth Restriction in Pigs
}

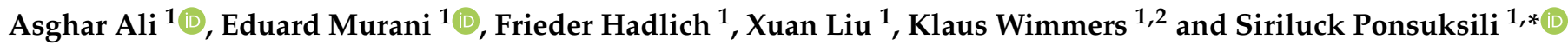 \\ 1 Leibniz Institute for Farm Animal Biology, Institute for Genome Biology, Wilhelm-Stahl-Allee 2, \\ 18196 Dummerstorf, Germany; ali@fbn-dummerstorf.de (A.A.); murani@fbn-dummerstorf.de (E.M.); \\ hadlich@fbn-dummerstorf.de (F.H.); liu.xuan@fbn-dummerstorf.de (X.L.); \\ klaus.wimmers@uni-rostock.de (K.W.) \\ 2 Faculty of Agricultural and Environmental Sciences, University Rostock, 18059 Rostock, Germany \\ * Correspondence: ponsuksili@fbn-dummerstorf.de; Tel.: +49-38208-68703; Fax: +49-38208-68702
}

check for updates

Citation: Ali, A.; Murani, E.; Hadlich, F.; Liu, X.; Wimmers, K.; Ponsuksili, S. Prenatal Skeletal Muscle Transcriptome Analysis Reveals Novel MicroRNA-mRNA Networks Associated with Intrauterine Growth Restriction in Pigs. Cells 2021, 10, 1007. https:// doi.org/10.3390/cells10051007

Academic Editor: Yasuhito Ishigaki

Received: 6 April 2021

Accepted: 21 April 2021

Published: 24 April 2021

Publisher's Note: MDPI stays neutral with regard to jurisdictional claims in published maps and institutional affiliations.

Copyright: (c) 2021 by the authors. Licensee MDPI, Basel, Switzerland. This article is an open access article distributed under the terms and conditions of the Creative Commons Attribution (CC BY) license (https:/ / creativecommons.org/licenses/by/ $4.0 /)$.

\begin{abstract}
Intrauterine growth restriction (IUGR) occurs in 15-20\% of pig neonates and poses huge economic losses to the pig industry. IUGR piglets have reduced skeletal muscle growth, which may persist after birth. Prenatal muscle growth is regulated by complex molecular pathways that are not well understood. MicroRNAs (miRNAs) have emerged as the main regulators of vital pathways and biological processes in the body. This study was designed to identify miRNA-mRNA networks regulating prenatal skeletal muscle development in pigs. We performed an integrative miRNA-mRNA transcriptomic analysis in longissimus dorsi muscle from IUGR fetuses and appropriate for gestational age (AGA) fetuses at 63 days post conception. Our data showed that 47 miRNAs and 3257 mRNAs were significantly upregulated, and six miRNAs and 477 mRNAs were significantly downregulated in IUGR compared to AGA fetuses. Moreover, 47 upregulated miRNAs were negatively correlated and can potentially target 326 downregulated genes, whereas six downregulated miRNAs were negatively correlated and can potentially target 1291 upregulated genes. These miRNA-mRNA networks showed enrichment in biological processes and pathways critical for fetal growth, development, and metabolism. The miRNA-mRNA networks identified in this study can potentially serve as indicators of prenatal fetal growth and development as well as postnatal carcass quality.
\end{abstract}

Keywords: IUGR; fetal growth; miRNAs; skeletal muscle development; miR-210

\section{Introduction}

Pig breeding programs have been traditionally focused on increasing litter size at birth and weaning [1,2]. Increased litter size affects litter uniformity, resulting in natural intrauterine growth restriction (IUGR) in some piglets [2]. Among all domestic animal species, pigs exhibit the most severe naturally occurring IUGR [3,4]. IUGR is defined as the inability of a fetus to reach its maximum growth potential, resulting in a fetal or birth weight more than two standard deviations (SD) below the mean weight for the corresponding gestational age or mean weight of littermates [4,5]. The inability of the placenta to supply or distribute sufficient nutrients and oxygen to the growing embryos/fetuses is one of the major factors in the pathogenesis of IUGR [6]. IUGR in pigs is associated with high morbidity and mortality during perinatal and pre-weaning periods, and can also lead to long term growth retardation and poor carcass quality $[4,7,8]$. IUGR-affected pigs have reduced feed conversion efficiency, decreased meat percentage, and high fat content in the carcass $[9,10]$. Along with impaired growth and development of embryo/fetus, IUGR can affect multiple fetal tissues and organ systems [4]. A recent study has shown that IUGR in piglets affects the structure, proliferation, and differentiation of skeletal muscle fibers [11]. 
Skeletal muscles account for nearly $45 \%$ of total body proteins and are the most abundant tissue in the body [12]. Reduced prenatal skeletal muscle growth and postnatal skeletal muscle mass are the characteristic features of IUGR $[13,14]$. Birth weight of piglets is directly affected by prenatal skeletal muscle development [15] and reflects the availability and utilization of nutrients for fetal growth and development [16]. Skeletal muscle growth and mass is largely determined during the prenatal period by the number and size of muscle fibers, and the number of muscle fibers does not increase after birth [17-19]. The contribution of the so-called satellite cells, a subpopulation of myogenic stem cells, to postnatal muscle growth is very subtle $[20,21]$. During the prenatal period, myofibers are formed in two waves [22]. In the first wave, myoblasts differentiate into small multinucleated primary myofibers, followed by a second wave of large secondary myofibers formation using primary myofibers as a template [22,23]. In pigs, the primary myofibers appear at around 35 days post conception (dpc) and last by $60 \mathrm{dpc}$, and the secondary myofibers start appearing at $55 \mathrm{dpc}$ and their number increases by many times by $75 \mathrm{dpc}[19,23]$. Formation of myofibers ceases and the total number of myofibers is established by $85-90 \mathrm{dpc}$ [17]. The ratio of secondary to primary myofibers is higher in large compared to small pig breeds $[24,25]$. The third wave is postnatal, starting at around 60 days after birth, during which no new muscle fibers are generated but there is a transition between slow-oxidative and fast-glycolytic fibers [23].

Impaired skeletal muscle development during the prenatal period can have a longlasting effect on muscle growth during the postnatal period, even after compensatory growth [26]. Therefore, a better understanding of the molecular pathways regulating prenatal skeletal muscle development is required to improve pigs' health as well as economic efficiency of pig industry. MicroRNAs (miRNAs) have emerged as important modulators of molecular pathways and cellular processes involved in animal development [27]. MiRNAs are small non-coding RNAs that are approximately 22 nucleotides long [28]. A single miRNA can regulate the expression of multiple genes through post-transcriptional repression and epigenetic regulation, making miRNAs the major regulators of gene expression [28-32]. Several studies have shown the role of miRNAs and their target genes in skeletal muscle growth and development at different prenatal and postnatal stages across different breeds of pigs [23,33-38].

In a previous study, we identified differentially expressed genes at seven key stages of myogenesis (14, 21, 35, 49, 63, 77 and $91 \mathrm{dpc}$ ) in two pig breeds, Pietrain (Pi) and Duroc, which differ evidently in muscle mass and structure [39]. In another study, we identified differentially expressed miRNAs in longissimus dorsi muscle (LDM) of German Landrace (DL) and Pi pig breeds at two prenatal stages (63 and $91 \mathrm{dpc}$ ) and one postnatal stage (180 days after birth) [33]. DL and Pi breeds also differ in muscularity, and Pi pigs are leaner and have a lower fat to meat ratio compared to DL pigs [33]. We reported that miRNAs from the miR-17 family and miR-17-92 cluster were upregulated at $63 \mathrm{dpc}$ and were also consistently higher in Pi pigs compared to DL pigs [33]. Predicted target genes of the differentially expressed miRNAs enriched several pathways related to muscle development [33]. Other studies have demonstrated that the miR-17 family regulates cell growth and development via the downregulation of transforming growth factor beta receptor II (TGFBR2) and insulin-like growth factor 1 (IGF1) [40,41].

More integrative studies are needed to uncover the molecular pathways involved in skeletal muscle growth and development and their role in pathophysiology of IUGR. In this study, we established an F2 population by crossing DL and Pi breeds and performed an integrative miRNA-mRNA transcriptomic analysis in LDM from IUGR and appropriate for gestational age (AGA) fetuses at $63 \mathrm{dpc}$. The aim of this study was to investigate gene networks associated with skeletal muscle development and pathophysiology of IUGR. This study provides valuable insights for the future use of miRNAs in diagnostics and therapeutics to improve pigs' growth. 


\section{Materials and Methods}

\subsection{Animals and Sample Collection}

Animal care and tissue collection procedures were approved by the Animal Care Committee of the Leibniz Institute for Farm Animal Biology and carried out in accordance with the approved guidelines for safeguarding good scientific practice at the institutions in the Leibniz Association and the measures were taken to minimize pain and discomfort and accord with the guidelines laid down by the European Communities Council Directive of 24 November 1986 (86/609/EEC). For this study, the animals were used for meat production and underwent no experimental treatment, diagnostic sampling, or any other intervention before killing therefore not requiring specific ethical approval. Animal handling as well as the killing was in accordance with applicable laws, relevant guidelines, and provisions for ethical regulations.

Analyses were done in a three-generation porcine F2 population, based on reciprocal crossbreeding DL and Pi breeds. One F1 father was mated to 11 F1 dams to produce a population of F2 fetuses. The sows were slaughtered, and the fetuses were extracted from the uteri and their weight was recorded. The discordant sib pair representing extremes for the fetuses' weight was selected from the 118 F2 fetuses. Fetuses from eight families with significant differences in weight were categorized as intrauterine growth restricted (IUGR; $n=12$ ) and appropriate for gestational age (AGA; $n=12$ ) groups. Fetuses weighing more than two SD below the mean weight of their littermates were categorized as IUGR. From each family, either only female or only male or both discordant sib pairs were placed in the IUGR and AGA groups. Longissimus dorsi muscle tissue (LDM) from AGA and IUGR fetuses was collected and immediately frozen in liquid nitrogen and stored at $-80^{\circ} \mathrm{C}$ until RNA extraction.

\subsection{RNA Isolation}

Total RNA was isolated from LDM using the Tri-Reagent and RNeasy Mini kit (Qiagen) with an on-column DNase treatment according to the manufacturer's protocol. The RNA integrity was assessed on a $1 \%$ agarose gel by electrophoresis. The RNA concentration was measured by a Nano Drop ND-1000 Spectrophotometer (PEQLAB). The quality and quantity of small RNA were assessed with an Agilent 2100 Bioanalyzer (Agilent) using an Agilent small RNA kit.

\subsection{Gene Expression Profiling}

The Porcine Snowball Microarray (Affymetrix) containing 47,880 probe sets was used to determine the expression profile of the LDM from F2 pigs at $63 \mathrm{dpc}$. Using the Affymetrix WT plus Expression kit and Genechip WT terminal labeling and hybridization kit according to the manufacturer's instructions, $500 \mathrm{ng}$ total RNA isolated from each tissue sample was used for cDNA synthesis and subsequent biotin labeling. Each of the labeled cRNA samples was hybridized on the array. The hybridization, washing, and scanning of the arrays were performed in accordance with the manufacturer's recommendations. Affymetrix GCOC1.1.1 software was used for quality control. Expression Console software was used for robust multichip average (RMA) normalization and the detection of present genes by applying the detection above background (DABG) algorithm. Further filtering was done by excluding transcripts with low signals and probe sets that were present in less than $80 \%$ of the samples. For further analyses, 11,288 probe sets passed the quality filtering and were used. The expression data are available in the Gene Expression Omnibus public repository with the GEO accession number GSE169092.

\subsection{MicroRNA Microarray Analysis}

Affymetrix customized microarrays (GEO: GPL14969) were used [42]. Targets for hybridization were prepared from miRNA with the FlashTag ${ }^{\mathrm{TM}}$ Biotin RNA Labeling Kit for Affymetrix GeneChip miRNA arrays (Genisphere, Hatfield, PA, USA) according to the manufacturer's recommendations. Briefly, $250 \mathrm{ng}$ of miRNA of each individual was 
poly(A)-tailed using ATP-poly-A-Polymerase, then FlashTag Biotin end-labelled. After the hybridisation of biotin-labelled complementary RNA, chips were washed and processed to detect biotin-containing transcripts by Streptavidin-PE (Phycoerythrin) conjugate, then were scanned on GeneChip scanner 3000 7G (Affymetrix, Santa Clara, USA). Data were extracted from the images, and spots were quantified and processed by quality filtering. Expression Console software was used for robust multichip average (RMA) normalization and the detection of present miRNAs by applying the DABG (detection above background) algorithm. Further filtering was done by excluding probe sets that were present in less than $80 \%$ of the samples and annotated miRNAs that had a sequence greater than or equal to 30 nucleotides in length. For further analysis, 675 probe sets passed the quality filtering and were used. The expression data are available in the Gene Expression Omnibus public repository with the GEO accession number GSE169093.

\subsection{Differentially Expressed Genes}

To determine whether there were differences in the gene expression based on fetal weight groups, the normalization expression data were served as dependent variables as input for variance analysis using JMP Genomics 9.0 (SAS Institute, Cary, NC, USA). Fetal weight groups and sex were regarded as fixed effects and dam as a random effect. The adjusting for multiple comparisons across the Type 3 tests for all of the effects was calculated using the post hoc Tukey-Kramer test. No miRNA reached 5\% FDR when comparing fetuses groups of IUGR and AGA. Therefore, we considered $p<0.05$ as a significant threshold. For mRNA data, $p$ values were adjusted according to the BenjaminiHochberg method to control for FDR [43]. Genes with FDR-adjusted $p$ values $<0.05$ were considered as differentially expressed.

\subsection{Prediction of miRNA Target Genes and Their Correlation Analysis}

To investigate the downstream target mRNAs for differentially expressed miRNAs between IUGR and AGA fetuses, 17,065 3'-UTR sequences, 16,857 5'-UTR sequences, and 20,310 coding sequences were extracted from the Sus scrofa genome (Sscrofa11.1) based on Ensembl annotation version 102. These sequences were fragmented into 2000 base pair fragments with a 50-base overlap. Using the whole mature miRNA sequence, RNAhybrid version 2.1.2 was used to predict the target genes of differentially expressed miRNAs by setting the parameter as for a single hit per target, human-based assumed $p$-value distribution, minimum free energy (MFE) threshold of $<-25 \mathrm{kcal} / \mathrm{mole}$, and helix constraint from base 2 to 7 [44,45]. The Pearson correlation between miRNAs and mRNAs was calculated. Only negatively correlating miRNA-mRNA pairs were used for further analyses.

\subsection{Correlation Network Analysis of miRNAs and Their mRNA Targets}

To identify the miRNAs previously linked with IUGR or skeletal muscle growth, a thorough PubMed search was performed using the easyPubmed package (version 2.13) [46] in the $\mathrm{R}$ programming environment. Ten upregulated miRNAs were identified as novel miRNAs with no previously reported association with IUGR or skeletal muscle growth. Using their negatively correlated downregulated target genes with correlation coefficient $\leq-0.3$, the correlation-based network was generated using the MetScape (version 3.1.3) plugin in the Cytoscape (version 3.6.1) environment [47].

\subsection{Enrichment Analysis of miRNAs and Target mRNAs}

Pairs of upregulated miRNAs were made with their downregulated target mRNAs, which are negatively correlated to each other (correlation coefficient $<-0.30$ ). Similarly, pairs of downregulated miRNAs were made with their upregulated target mRNAs, which are negatively correlated to each other (correlation coefficient $<-0.30$ ). In the first step, miRNA-mRNA pairs from upregulated miRNAs and downregulated genes were used for downstream gene ontology analysis for biological processes and KEGG pathways 
enrichment analysis using the ClueGO (version 2.5.1) and Cluepedia (version 1.5.7) plugin in Cytoscape (version.3.8.2) environment [48-50]. In the second step, miRNA-mRNA pairs from downregulated miRNAs and upregulated genes were used for over-representation analysis (ORA) for gene ontology for biological processes and KEGG pathways enrichment analysis using the WEB-based Gene Set Analysis Toolkit (WebGestalt) [51,52]. A hypergeometric test was used for enrichment analysis and Benjamini-Hochberg correction was used for multiple testing correction and the Sus scrofa genome assembly as a reference. The KEGG pathways and gene ontologies with FDR $\leq 0.05$ were considered significantly enriched.

\subsection{Validation of Sequencing Data by $q P C R$}

To validate miRNA and mRNA results, transcripts of some differentially expressed miRNAs and mRNA were quantified in LDM from AGA and IUGR groups by qPCR using the Fluidigm BioMark HD System. Briefly, $250 \mathrm{ng}$ of each RNA sample was reverse transcribed using the reverse transcription kit (Invitrogen) following the manufacturer's protocol. For specific target amplification, $5 \mu \mathrm{L}$ pre-amplification sample mixture for each cDNA was prepared by mixing $2.5 \mu \mathrm{L}$ PreAmp Master Mix, $1.25 \mu \mathrm{L}$ of cDNA, $1 \mu \mathrm{L}$ PreAmp Master Mix, $0.5 \mu \mathrm{L}$ Pooled Delta Gene Assay Mix (500 nM), and $0.75 \mu \mathrm{L}$ water. These reactions were incubated at $95{ }^{\circ} \mathrm{C}$ for $10 \mathrm{~min}$, followed by 10 cycles of $15 \mathrm{~s}$ at $95{ }^{\circ} \mathrm{C}$ and $4 \mathrm{~min}$ at $60{ }^{\circ} \mathrm{C}$, and then infinite hold at $4{ }^{\circ} \mathrm{C}$. After incubation, the samples were cleaned using the exonuclease I treatment method. Cleaned samples were diluted 10-fold using a DNA suspension buffer. Fluidigm quantitative measurement runs were carried out with 96.96 dynamic arrays (Fluidigm Corporation, CA, USA) according to the manufacturer's instructions. The data were analyzed with real-time PCR analysis software in the BioMark HD instrument (Fluidigm Corporation, San Francisco, CA). Actin beta (ACTB) and glyceraldehyde-3-phosphate dehydrogenase (GAPDH) were used as housekeeping controls for mRNA quantification, and cel-miR-39-3p was used as the internal control for miRNA quantification, and calculations were based on the $2^{-\Delta \mathrm{Ct}}$ method. Sixteen femtomole cel-miR-39-3p RNA spike-in, corresponding to $2 \times 10^{8}$ copy number of transcripts, was added in each miRNA sample before reverse transcription. The miRNA and mRNA primer sequences are listed in Table S1.

\section{Results}

\subsection{Phenotypic Trait and Differential Expression of miRNAs and $m R N A s$}

Discordant sibling pair design including eight different dams and one sire was used to group all fetuses based on their weight. Using the above described criteria, fetuses collected at $63 \mathrm{dpc}$ were divided in two groups-intrauterine growth restricted fetuses (IUGR; $n=12$ ) and appropriate for gestational age fetuses (AGA; $n=12$ ). To minimize the effect of sex, an equal number of fetuses of the same sex from each dam were placed in both groups. Details of fetal phenotype from both groups are provided in Table 1 . The mean weight of IUGR fetuses (113.60 $\pm 5.32 \mathrm{~g})$ was significantly low compared to AGA fetuses $(175.96 \pm 4.5 \mathrm{~g})$ (Figure 1$)$. 
Table 1. Phenotype of fetuses in AGA and IUGR groups from one sire and eight dams.

\begin{tabular}{cccccccc}
\hline \multicolumn{2}{c}{ AGA } & \multicolumn{5}{c}{ IUGR } \\
\hline Fetus ID & $\begin{array}{c}\text { Fetal } \\
\text { Weight (g) }\end{array}$ & Dam & Fetal Sex & Fetus ID & $\begin{array}{c}\text { Fetal } \\
\text { Weight (g) }\end{array}$ & Dam & Fetal Sex \\
\hline E352 & 175 & 1 & Male & E355 & 106.2 & 1 & Male \\
E363 & 182 & 1 & Male & E360 & 94.2 & 1 & Male \\
E370 & 154.4 & 2 & Female & E376 & 125.9 & 2 & Female \\
E272 & 183 & 3 & Female & E274 & 108 & 3 & Male \\
E283 & 186.6 & 3 & Male & E281 & 137.1 & 3 & Female \\
E297 & 194.4 & 4 & Male & E303 & 132.1 & 4 & Male \\
E324 & 196.6 & 5 & Male & E320 & 125.5 & 5 & Male \\
E327 & 192.8 & 5 & Male & E329 & 116.9 & 5 & Male \\
E307 & 155.5 & 6 & Female & E311 & 90.4 & 6 & Female \\
E313 & 157.5 & 6 & Male & E312 & 78.4 & 6 & Male \\
E377 & 163.1 & 7 & Female & E384 & 118.1 & 7 & Female \\
E340 & 170.6 & 8 & Female & E338 & 130.4 & 8 & Female \\
\hline
\end{tabular}

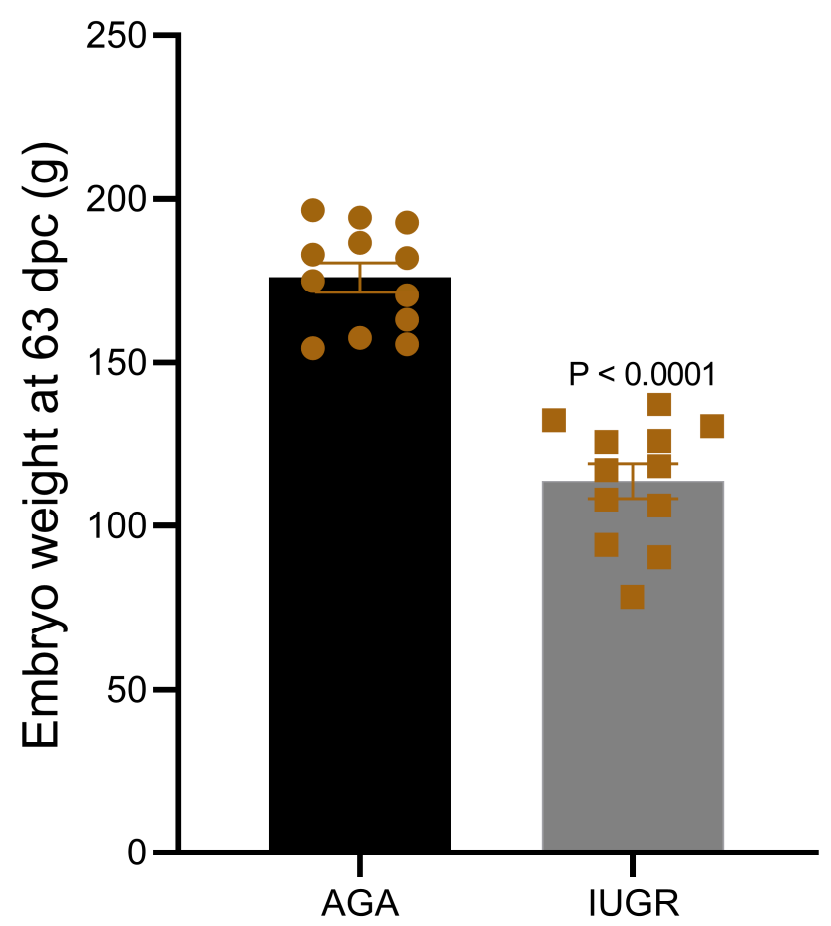

Figure 1. Weight of pig fetuses at $63 \mathrm{dpc}$ in IUGR and AGA groups.

The expression of 675 miRNA probe sets was measured to investigate their association with the body weight of pig fetuses at $63 \mathrm{dpc}$. A total of $47 \mathrm{miRNAs}$ were significantly upregulated $(p<0.05)$ and six miRNAs were significantly downregulated $(p<0.05)$ in longissimus dorsi muscle (LDM) from IUGR fetuses compared to AGA fetuses (Figure 2). The top five significantly different miRNA between groups were miR-210, miR-30, miR-173p, miR-199a, and miR-34a, which were all upregulated in IUGR fetuses. Moreover, out of 47,880 mRNA probe sets on the snowball microarray, 11,288 quality-filtered probe sets were further analyzed. A total of 477 genes were significantly downregulated (FDR $<0.05)$ and 3257 genes were significantly upregulated (FDR < 0.05) in LDM from IUGR fetuses compared to AGA fetuses (Figure 3). 


\section{Color Key}
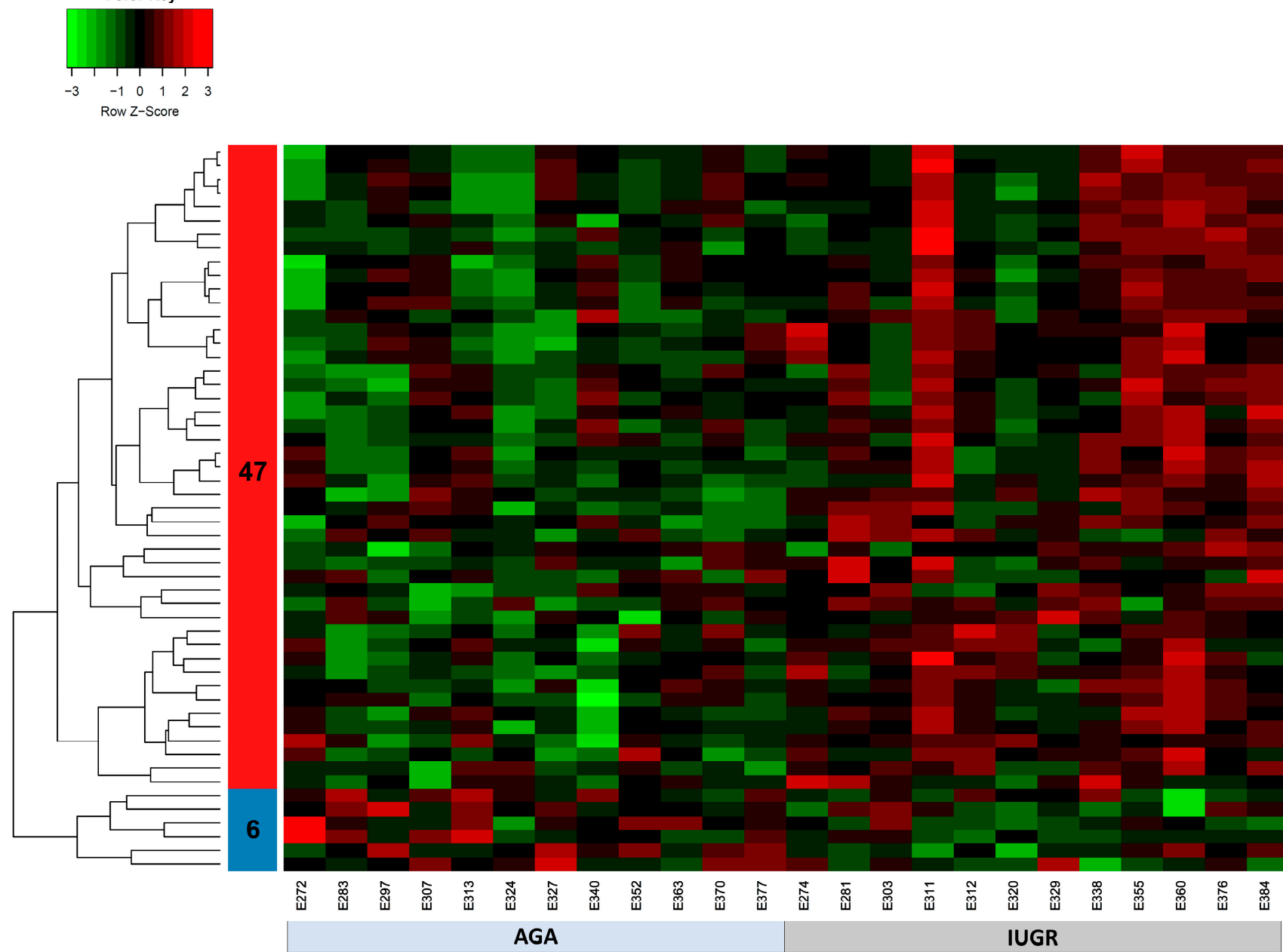

Figure 2. Heatmap of differentially expressed miRNAs $(p<0.05)$ in AGA and IUGR groups. Heatmap of miRNAs expression profiles was generated using the hierarchical clustering method of heatmap.2 function of gPlots (version 3.0.1) [53] Bioconductor Package in the R Programming environment (version 4.0.3). Forty-seven miRNAs in cluster 1 were upregulated and six miRNAs in cluster 2 were downregulated in LDM from IUGR compared to AGA fetuses. Upregulated miRNAs are marked in red, downregulated miRNAs are colored in green, and black color reflects no difference in expression levels. 


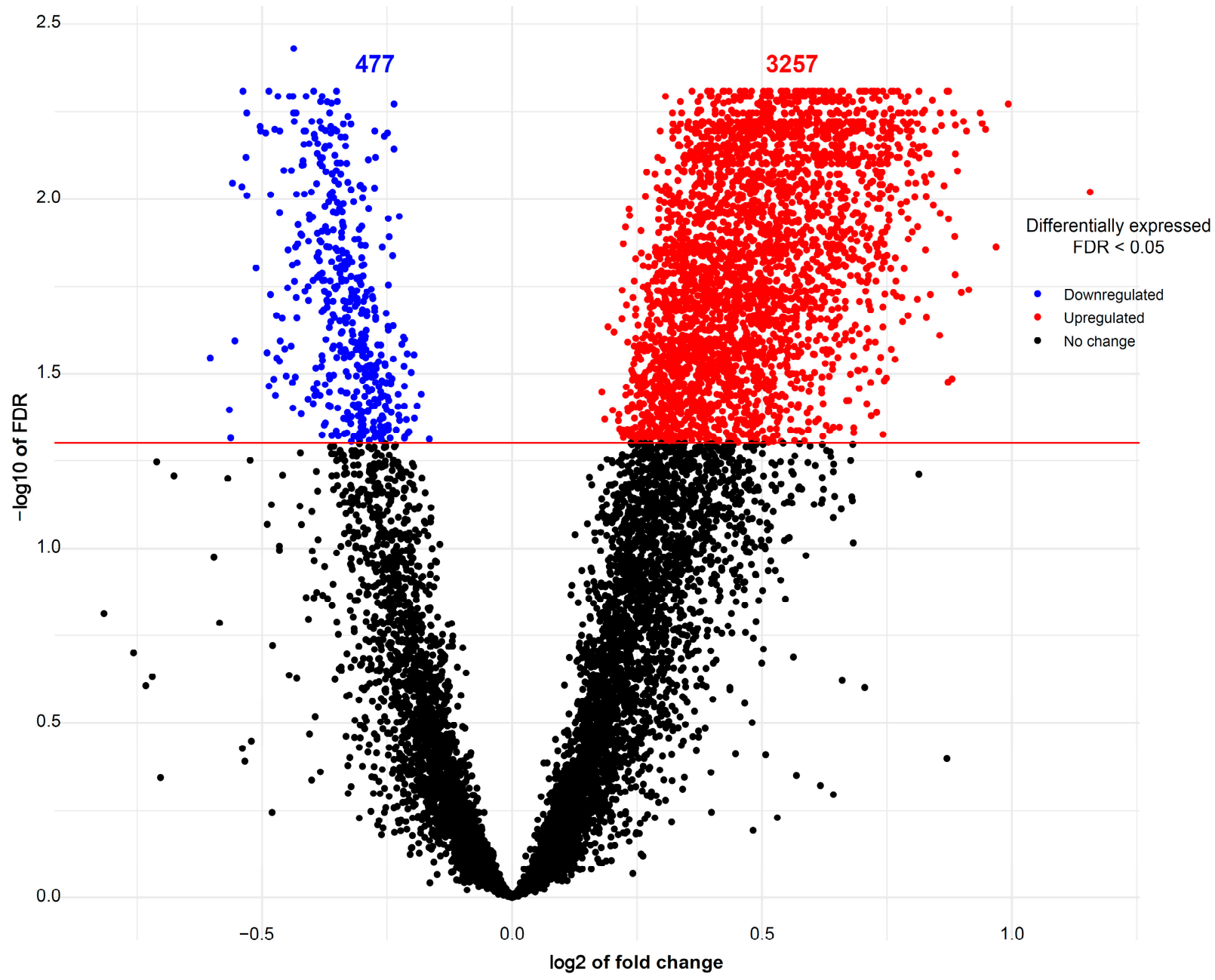

Figure 3. Volcano plots of mRNAs differentially expressed between AGA and IUGR groups. Red spots represent upregulated mRNAs and blue spots indicate downregulated mRNAs in LDM from IUGR fetuses compared to AGA fetuses. Black spots represent mRNAs that did not show changes between AGA and IUGR groups.

\subsection{MicroRNA-mRNA Networks}

Correlation between 47 upregulated miRNAs and 477 downregulated mRNAs in IUGR fetuses was calculated, and miRNA-mRNA pairs with correlation coefficient $\leq-0.3$ were used for further analysis. Using RNAhybrid, we found potential target genes of 47 upregulated miRNAs in their negatively correlated downregulated genes. Our analysis showed that 47 upregulated miRNAs can potentially target 326 downregulated genes, which are also negatively correlated to these miRNAs. A total of 3292 possible miRNA-mRNA pairs that meet the described criteria are listed in Table S2. The correlation coefficient in these pairs ranges from -0.3 to -0.87 (Table S2). These miRNAmRNA pairs were used for further downstream analysis. From these miRNA-mRNA pairs, we also analyzed a number of potential negatively correlated target genes of each upregulated miRNA. MiR-34, primarily known as a tumor-suppressing miRNA, was upregulated in IUGR fetuses and can target 232 downregulated genes, which are also negatively correlated to miR-34 (Figure 4A). Similarly, miR-210, a hypoxia responsive miRNA that has been frequently linked with IUGR in humans, was upregulated in IUGR fetuses and can target 220 downregulated genes, which are also negatively correlated to miR-210 (Figure 4A). The top 10 upregulated miRNAs and the total number of their potential targets among their negatively correlated downregulated genes are provided in Figure 4A. 


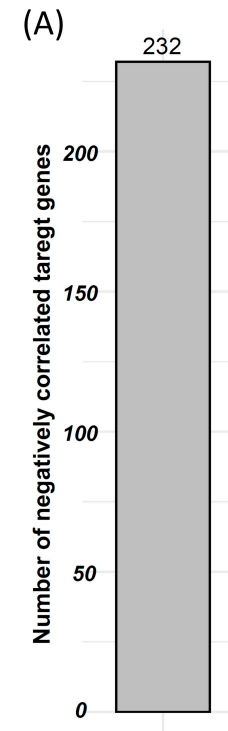

(B)
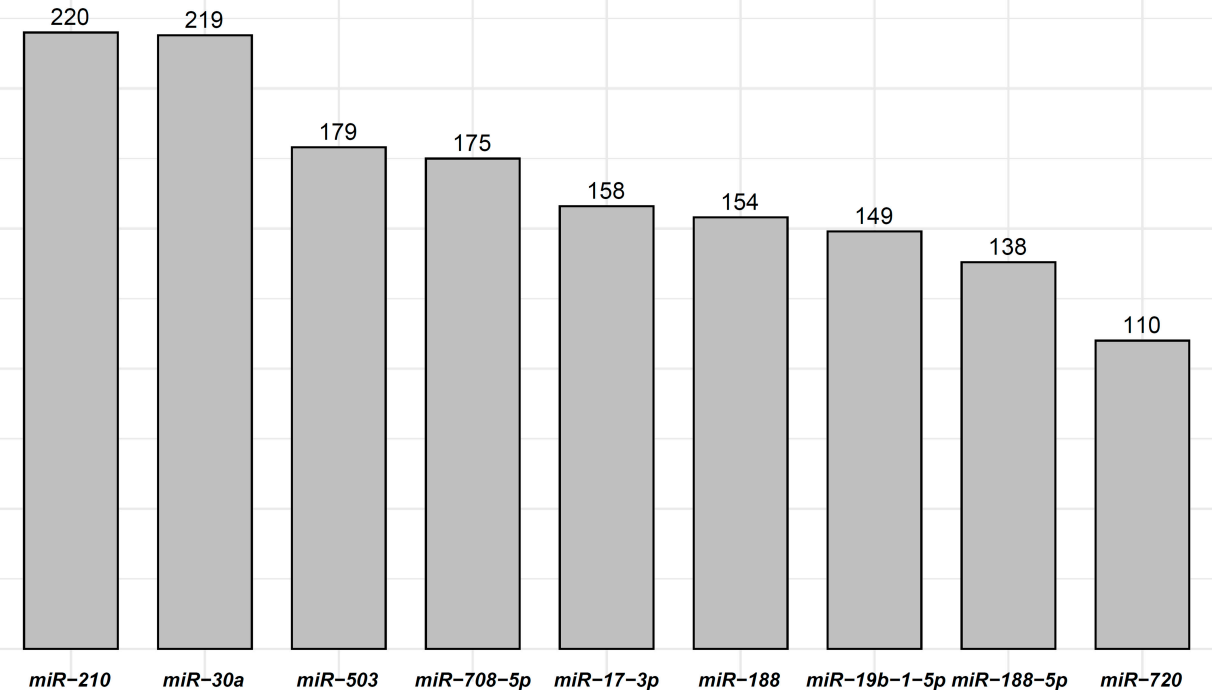

Upregulated miRNAs

$m i R-720$

053

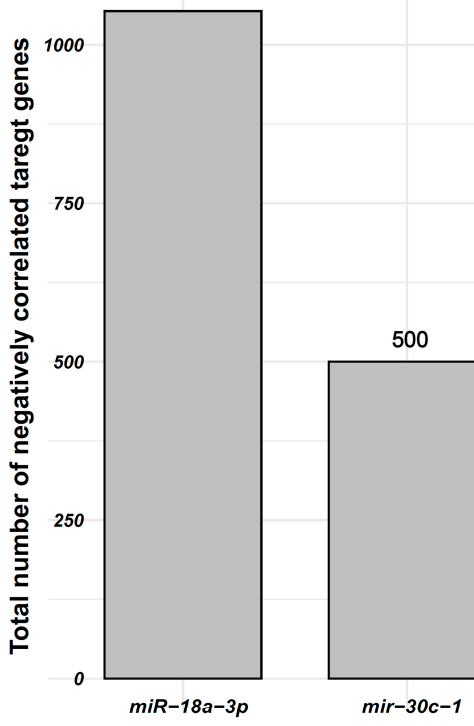

187

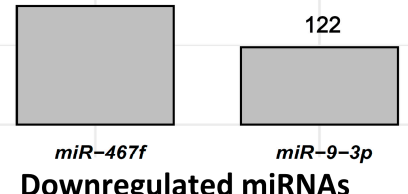

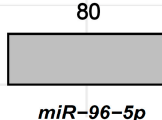

$\operatorname{miR}-96-5 p$

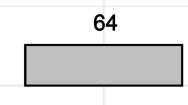

$m i R-223$

Figure 4. Differentially expressed miRNAs and their negatively correlated potential target genes. (A) Top 10 upregulated miRNAs and the number of their negatively correlated and downregulated target genes. (B) Downregulated miRNAs and the number of their negatively correlated and upregulated target genes.

We also measured the correlation between six downregulated miRNAs and 3257 upregulated mRNAs, and miRNA-mRNA pairs with correlation coefficient $\leq-0.3$ were used in further analysis. Using RNAhybrid, we found target genes of six downregulated miRNAs in their negatively correlated upregulated genes. Our analysis showed that six downregulated miRNAs can target 1291 upregulated genes, which are also negatively correlated to these miRNAs. A total of 2007 possible miRNA-mRNA pairs that meet the described criteria are listed in Table S3. The correlation coefficient in these pairs ranges from -0.3 to -0.76 (Table S3). These miRNA-mRNA pairs were used for further downstream analysis. Six downregulated miRNAs including miR-18a-3p, miR-30c-1, miR-467f, miR-93p, miR-96-5p, and miR-223 can target 1053, 500, 187, 122, 80, and 64 upregulated genes, respectively (Figure 4B). 


\subsection{Gene Ontology and KEGG Pathway Enrichment Analysis of Downregulated Genes}

We used 47 upregulated miRNAs and their 326 downregulated target genes (Table S2) for gene ontology and KEGG pathway enrichment analysis using the ClueGO (version 2.5.1) and Cluepedia (version 1.5.7) plugin in Cytoscape (version.3.8.2) environment [48-50]. The results of gene ontology enrichment analysis showed that the downregulated genes significantly enriched biological processes vital for muscle growth and development, including myoblast fusion, myotube differentiation, and regulation of angiogenesis (Figure 5). The other important enriched biological processes included the regulation of embryonic development, bone remodeling, placental blood vessel development, regulation of multicellular organism growth, and epidermal growth factor receptor signaling pathway (Figure 5). Figure 5 also shows the upregulated miRNAs targeting the genes enriching important biological processes. A complete list of biological processes significantly enriched by downregulated genes is provided in Table S4. Similarly, KEGG pathways enrichment analysis showed that 326 downregulated genes significantly enriched important KEGG pathways including the calcium signaling pathway, Rap1 signaling pathways, PPAR signaling pathway, thyroid hormone signaling pathway, glycolysis/gluconeogenesis, HIF-1 signaling pathway, Hippo signaling pathways, and tight junction (Figure 6). Figure 6 also shows the upregulated miRNAs targeting the genes enriching important KEGG pathways. A complete list of significantly enriched KEGG pathways by downregulated genes is provided in Table S5.

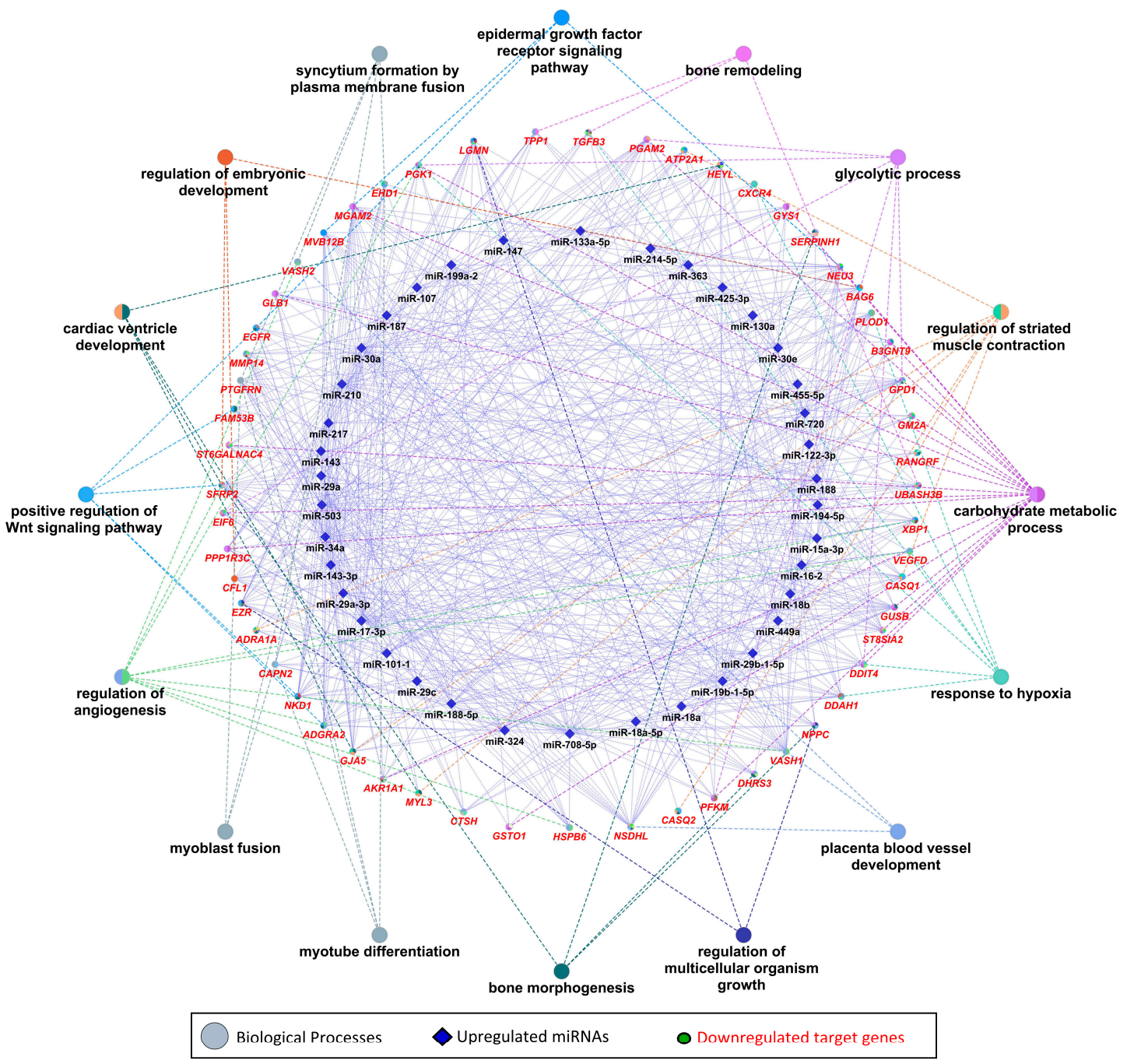

Figure 5. Enrichment analysis of downregulated genes, which are negatively correlated to and targeted by upregulated 
miRNAs, in gene ontologies for biological processes, derived using the ClueGO (version 2.5.1) and Cluepedia (version 1.5.7) plugin in Cytoscape (version 3.8.2) environment. Eclipses with red labels indicate the genes, and different pie colors in gene shapes indicate their enrichment in multiple biological processes. A complete list of biological processes enriched by downregulated genes is provided in Table S3.

\begin{tabular}{|l|l|}
\hline KEGG ID & KEGG Term \\
\hline KEGG:04020 & Calcium signaling pathway \\
\hline KEGG:04015 & Rap1 signaling pathway \\
\hline KEGG:03320 & PPAR signaling pathway \\
\hline KEGG:04919 & Thyroid hormone signaling pathway \\
\hline KEGG:00010 & Glycolysis / Gluconeogenesis \\
\hline KEGG:04066 & HIF-1 signaling pathway \\
\hline KEGG:04390 & Hippo signaling pathway \\
\hline KEGG:04530 & Tight junction \\
\hline
\end{tabular}

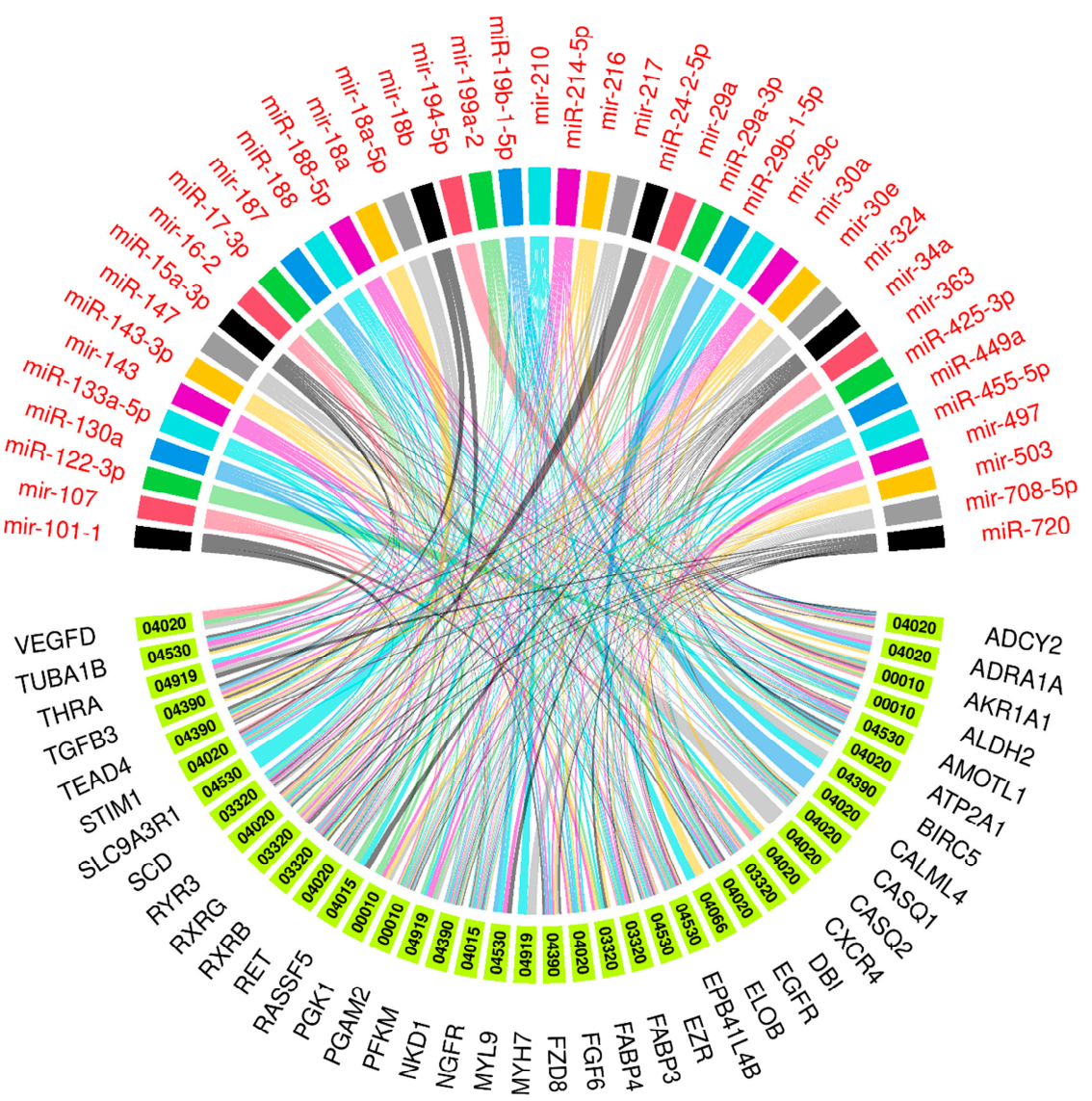

Figure 6. Enrichment analysis of downregulated genes, which are negatively correlated to and targeted by upregulated miRNAs, in KEGG pathways derived using the ClueGO (version 2.5.1) and Cluepedia (version 1.5.7) plugin in Cytoscape (version 3.8.2) environment. A complete list of KEGG pathways enriched by downregulated genes is provided in Table S3.

\subsection{Gene Ontology and KEGG Pathway Enrichment Analysis of Upregulated Genes}

In the next step, we used six downregulated genes and their 1291 upregulated target genes (Table S3) for gene ontology and KEGG pathway enrichment analysis using ORA in WebGestalt $[51,52]$. ORA results showed that the upregulated genes are enriched in important biological processes (Figure 7A). Interestingly, the top 10 enriched biological processes are mainly involved in metabolism, including macromolecule metabolism, primary metabolic process, cellular metabolic process, and nucleic acid metabolic process (Figure 7A). Similarly, KEGG pathways ORA analysis showed that the upregulated genes enriched important KEGG pathways including ubiquitin mediated proteolysis, the mRNA surveillance pathway, thyroid hormone signaling pathways, and the MAPK signaling pathway (Figure 7B). 


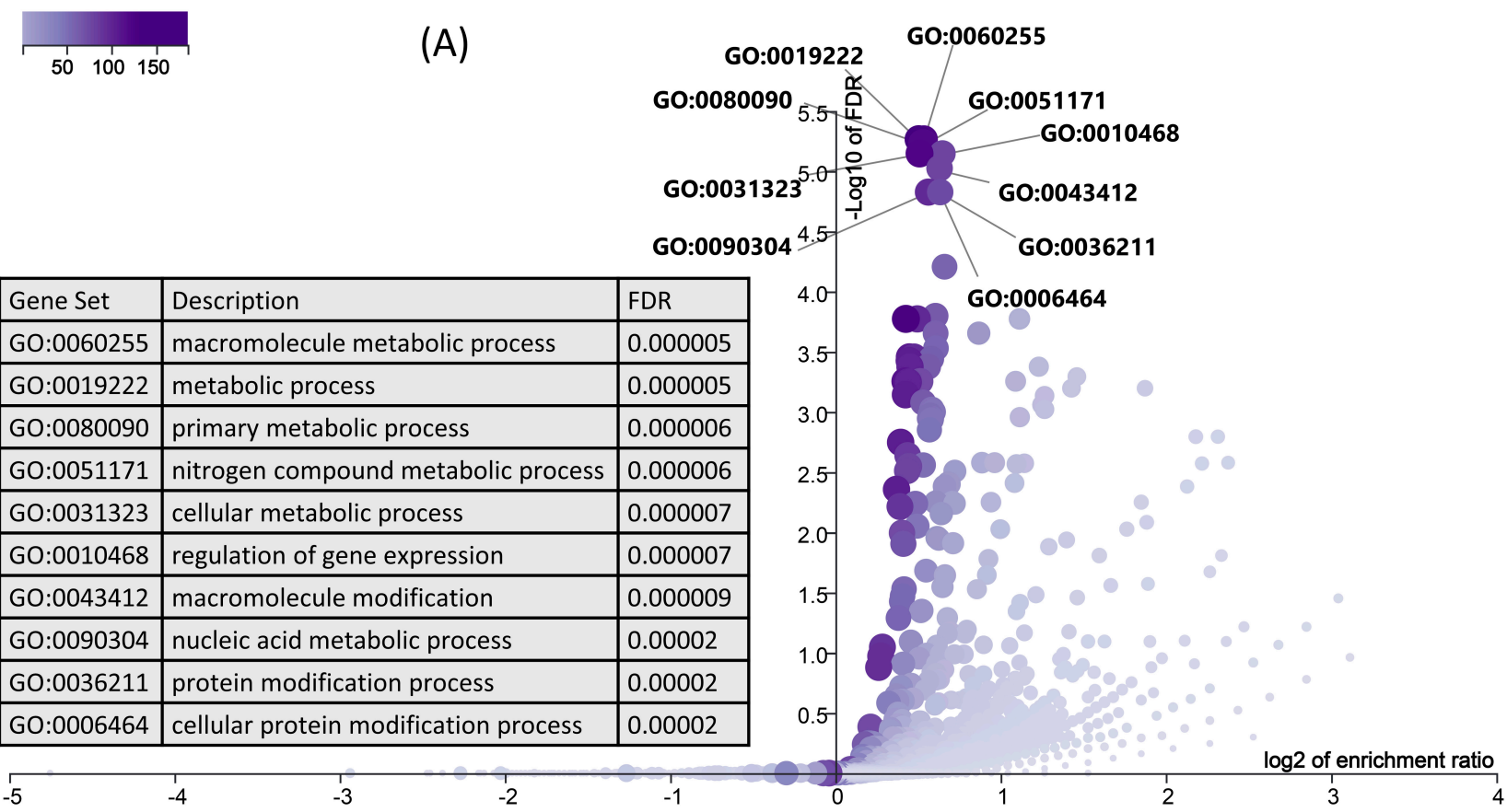

$\begin{array}{lllll}10 & 20 & 30 & 40 & \end{array}$

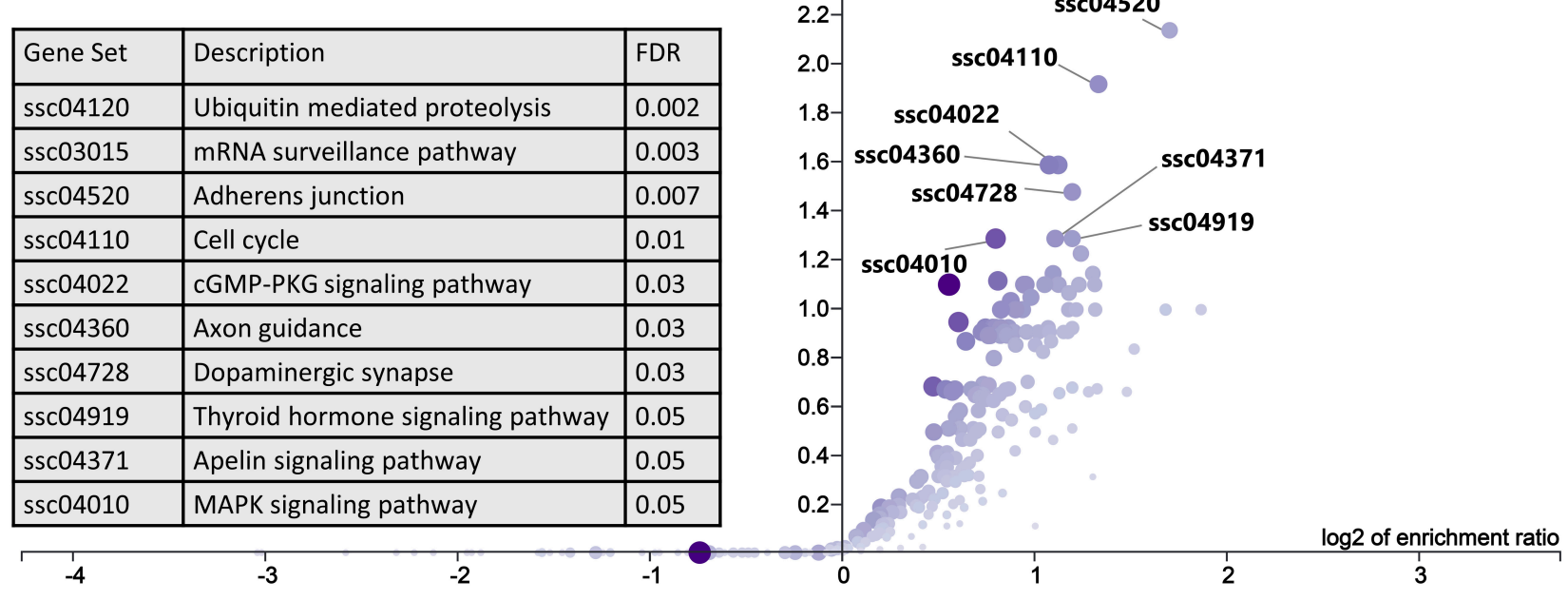

Figure 7. ORA results for upregulated genes, which are negatively correlated and targeted by downregulated miRNAs. (A) Biological processes significantly enriched by upregulated genes in LDM from IUGR fetuses at 63 dpc, derived using WebGestalt. A complete list of biological processes enriched by downregulated genes is provided in Table S4. (B) KEGG pathways enriched by upregulated genes in LDM from IUGR fetuses at $63 \mathrm{dpc}$, derived using WebGestalt.

\subsection{Novel miRNA-mRNA Networks}

Other than previously known miRNAs, we also found 10 novel miRNAs that were upregulated in LDM of IUGR fetuses and have not been previously linked to either IUGR or skeletal muscle growth. These novel miRNAs included miR-187, miR-188, miR-188-5p, miR-18b, miR-216, miR-219a-5p, miR-449a, miR-616-3p, miR-720, and miR-95. Out of a total of 326 downregulated target genes, the upregulated novel miRNAs are negatively correlated and can target 253 downregulated genes (Figure 8). A complete list of the novel miRNA-mRNA pairs is provided in Table S6. 
(A) miRNAs previously linked to

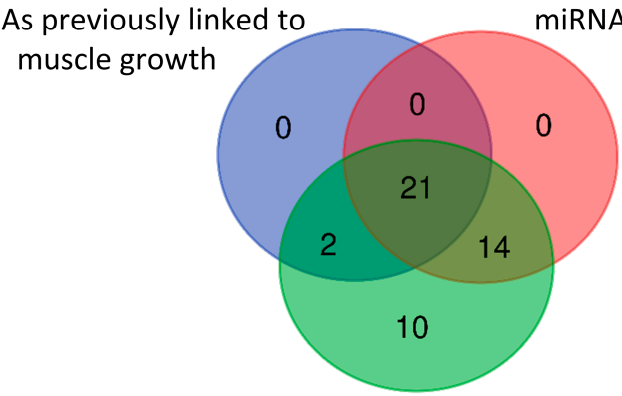

miRNAs previously linked to

IUGR

Upregulated miRNAs in current study

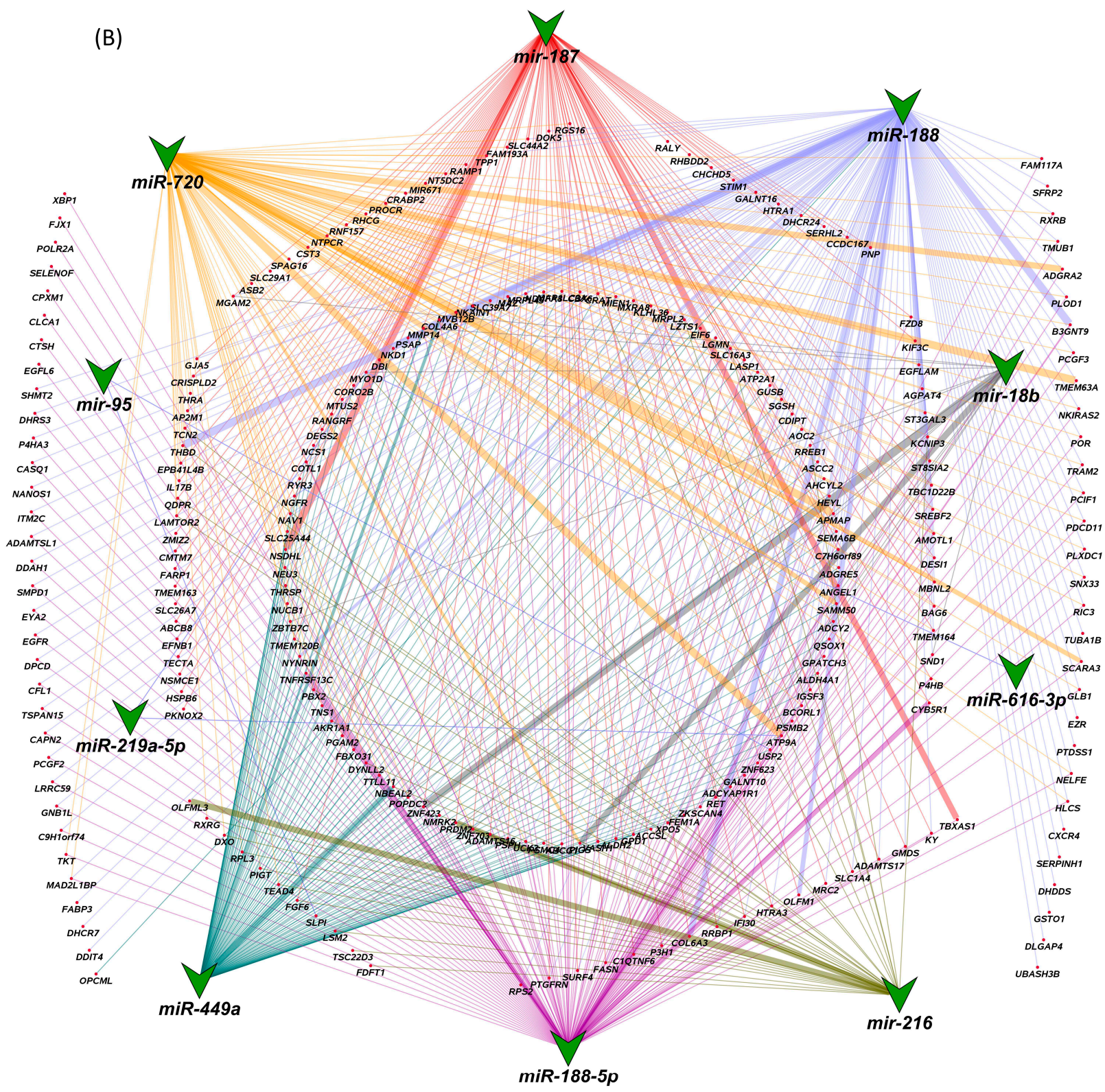

Upregulated miRNAs

O Negatively correlated target genes

Correlation based edges

Figure 8. Novel miRNA-mRNA networks. (A) Comparison of upregulated miRNAs in LDM from IUGR fetuses with previously identified miRNAs associated with IUGR and skeletal muscle growth. (B) Correlation network between novel upregulated miRNAs and their negatively correlated downregulated target genes. A complete list of novel miRNA-mRNA pairs is provided in Table S5. Correlation coefficient in these pairs ranges from -0.3 to 0.74 . 


\subsection{Validation by $q P C R$}

We validated the holistic expression analyses through qPCR for four upregulated miRNAs including miR-210, miR-101-1, miR-30a, and miR-17-3p, two downregulated genes including thyroid hormone responsive (THRSP) and phosphoglycerate mutase 2 (PGAM2), and two upregulated genes including protein phosphatase 3 catalytic subunit alpha (PPP3CA) and insulin like growth factor 1 (IGF1). All miRNAs and mRNAs quantified through qPCR showed the same trend of regulation as seen in the sequencing results (Figure 9).

(A)

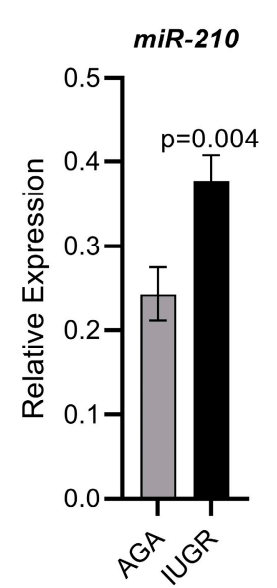

(B)

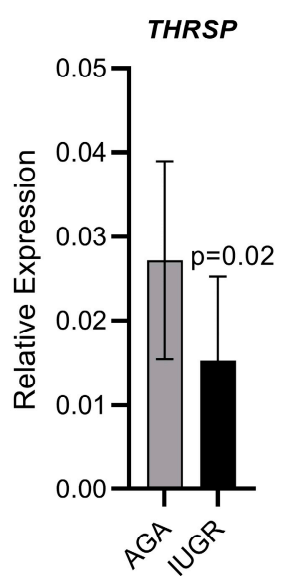

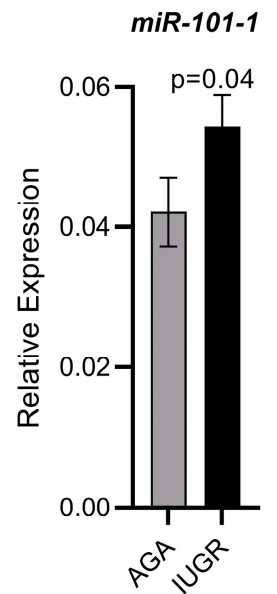

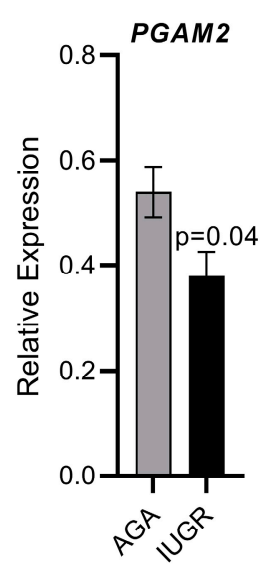

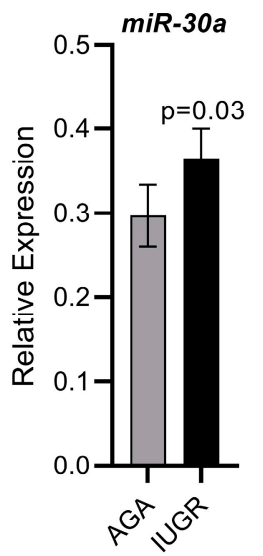

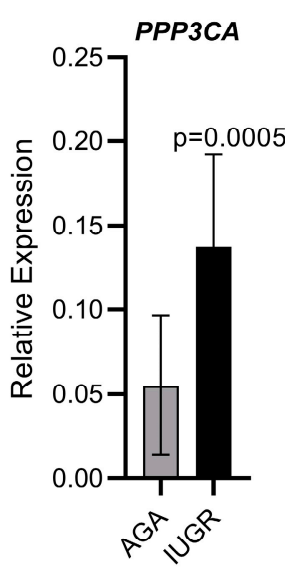

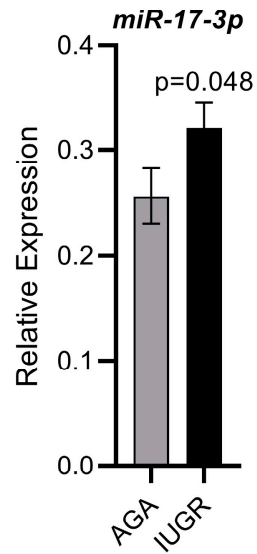

IGF1

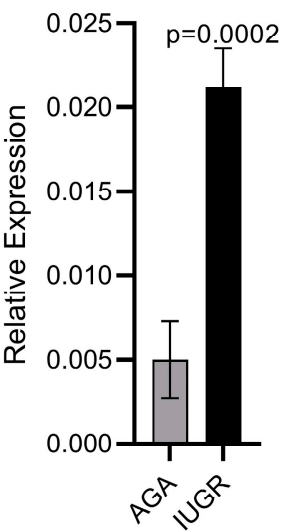

Figure 9. Validation of sequencing data by qPCR for selected miRNAs and mRNAs. (A) Relative expression of four upregulated miRNAs quantified through qPCR. (B) Relative expression of two downregulated and two upregulated mRNAs quantified through qPCR.

\section{Discussion}

Normal prenatal skeletal muscle growth and development is a major determinant of the postnatal growth and survival and carcass quality of pigs [17-19]. The dynamic transition between different cell types during prenatal skeletal muscle development is regulated by numerous signaling pathways and transcription factors, and their dysregulation can lead to abnormal muscle development and reduced muscle mass [54]. We found significantly increased levels of 47 miRNAs in longissimus dorsi muscle (LDM) from IUGR fetuses compared to AGA fetuses at $63 \mathrm{dpc}$ (Figure 2). In recent studies, we investigated the role of miRNAs in pathophysiology of pregnancy-associated disorders and identified potential biomarker miRNAs for pregnancy complications [55-57]. Out of 47 upregulated miRNAs reported in this study, dysregulation of five miRNAs including miR-34a, miR-210, miR-199a, miR-363, and miR-16 in placenta or maternal circulation has 
been previously linked with pathophysiology of IUGR [57,58]. According to our results, from downregulated genes in LDM from IUGR fetuses, miR-34a, miR-210, miR-199a, miR363 , and miR-16 can potentially target 232, 220, 99, 29, and 29 genes, respectively (Table S2). Previous evidence of dysregulation of miR-34a, miR-210, miR-199a, miR-363, and miR-16 in placenta or maternal circulation in IUGR pregnancies, and upregulation of these miRNA in skeletal muscle of IUGR fetuses in our study, indicates the diagnostic and therapeutic importance of these miRNAs.

The wide range of genes targeted by miR-34a and miR-210 makes them more interesting candidate miRNAs that are critical in the pathophysiology of IUGR. Previous studies have shown that miR-34a regulates skeletal muscle ageing [59], and its circulating levels in the body increase with age [60]. Myostatin (MSTN), a well-studied inhibitor of skeletal muscle growth and development, operates through miR-34a, and C2C12 cells treated with MSTN show an increase in miR-34a level [61]. Therefore, increased miR-34a in prenatal skeletal muscles can negatively regulate muscle growth leading to IUGR. Out of 326 downregulated genes in LDM from IUGR fetuses in this study, miR-34a can potentially target 232 genes, which indicates the involvement of miR-34a in a wide range of molecular pathways. Induced under hypoxia, miR-210 is one of the most studied miRNAs [62]. During skeletal muscle development, miR-210 is induced upon myogenic differentiation and its activation is regulated by hypoxia-inducible factor 1- $\alpha$ (HIF1A) [63]. It also regulates energy balance, mitochondrial function, and apoptosis in skeletal muscle cells [64]. According to our data, out of 326 downregulated genes in LDM from IUGR fetuses, miR-210 can potentially target 220 genes involved in critical biological processes for muscle growth and fetal development.

Collectively, 47 upregulated miRNAs are negatively correlated to and can target 326 downregulated genes in LDM from IUGR fetuses. Downstream enrichment analysis shows that the downregulated genes are involved in several biological processes and pathways critical for skeletal muscle development and fetal growth, such as myoblast fusion, angiogenesis, embryonic development, and bone morphogenesis (Figure 5). Myoblast fusion is a critical process during prenatal skeletal muscle development, as well as during postnatal muscle regeneration $[65,66]$. Plasma membrane fusion of mononucleated myoblasts with each other or with previously formed syncytial myofibers is the primary mechanism of increasing muscle mass [67]. In current study, among the downregulated genes in skeletal muscles from IUGR fetuses, calpain 2 (CAPN2), EH-domain containing 1 (EHD1), prostaglandin F2 receptor negative regulator (PTGFRN), and vasohibin-2 (VASH2) are involved in myoblast fusion (Figure 5). These genes were also identified as potential targets of upregulated miRNAs. CAPN2 can be targeted by miR-188, miR-188-5p, miR-19b-1-5p, miR-29b-1-5p, miR-30a, miR-503, and miR-708-5p; EHD1 is a potential target of miR-17-3p, miR-210, miR-34a, miR-425-3p, and miR-708-5p; and PTGFRN can be potentially targeted by miR-133a-5p, miR-15a-3p, miR-17-3p, miR-187, miR-188, miR-188-5p, miR-19b-1-5p, miR-30a, miR-30e, miR-324, miR-34a, miR-503, and miR-708-5p; whereas VASH2 is a potential target of miR-210. Three out of these four genes are regulated by miR-34a and/or $\mathrm{miR}-210$. We suggest that dysregulation of the genes involved in myoblast fusion during embryonic stages can impair skeletal muscle development and lead to IUGR.

Skeletal muscle is a highly vascularized tissue, and a microvasculature unit in skeletal muscle is comprised of three to four adjacent myofibers and five to 10 capillaries [68]. Vascularization of skeletal muscle is critical for its proper growth, development, and regeneration [69]. Our results show that six downregulated genes including cathepsin $\mathrm{H}$ (CTSH), heat shock protein beta-6 (HSPB6), secreted frizzled related protein 2 (SFRP2), VASH2, vascular endothelial growth factor D (VEGFD), and X-box binding protein 1 (XBP1) are associated with positive regulation of angiogenesis (Table S4). These six downregulated genes are targeted by different upregulated miRNAs. CTSH can be targeted by miR-15a3p, miR-188-5p, mir-194-5p, miR-19b-1-5p, mir-217, miR-29b-1-5p, mir-34a, and mir-503; HSBP6 can be targeted by mir-187, mir-210, mir-29a, miR-29a-3p, mir-29c, mir-30a, mir-34a, and mir-708-5p; SFRP2 is a potential target of miR-130a, miR-143-3p, miR-15a-3p, miR-17- 
3p, miR-188, miR-19b-1-5p, miR-210, miR-214-5p, miR-29a, miR-29a-3p, miR-29c, miR-34a, miR-455-5p, miR-503, and miR-708-5p; VASH2 is targeted by miR-210; and VEGFD is targeted by miR-107, miR-16-2, miR-17-3p, and miR-324; whereas XBP1 can be targeted by miR-15a-3p, miR-17-3p, miR-188-5p, miR-19b-1-5p, miR-210, miR-30a, miR-324, miR-34a, miR-425-3p, miR-503, and miR-708-5p (Figure 5, Table S2). Five out of six genes involved in positive regulation of angiogenesis are regulated by miR-210 and/or miR34a. We suggest that reduced expression of these genes in skeletal muscles during prenatal stages can not only affect prenatal skeletal muscle growth leading to IUGR, but can also have long-lasting postnatal affects.

Out of 47 upregulated miRNAs in LDM from IUGR fetuses, 37 miRNAs have been previously linked to either IUGR or skeletal muscle growth, 21 of which have been associated with both IUGR and skeletal muscle growth (Figure 8A, Table S6). Of these 21 miRNAs, dysregulation of miR-133a [70-74] and miR-29a [75,76] have been most often associated with IUGR and skeletal muscle growth. MiR-133a is one of the most studied muscle-specific miRNAs (myomiRs) [71], which promotes myoblast differentiation and reduces their proliferation [70]. According to our results, miR-133a is upregulated in LDM from IUGR fetuses and is negatively correlated and can potentially target 82 downregulated genes (Table S2). Our results further demonstrate that miR-133a target genes enriched biological processes critical for skeletal muscle growth and fetal development, including regulation of angiogenesis, placenta blood vessel development, myotube differentiation, and myoblast fusion (Figure 5). MiR-29a is a member of the miR-29 family of miRNAs which contains three members; miR-29a, miR-29b, and miR-29c [75]. By regulating the Wnt signaling pathway, miR-29a/b promotes osteogenesis $[77,78]$. Members of the miR-29 family target myogenin, serine/threonine kinase 3 (AKT3), and atrophy-related genes such as muscle ring-finger protein-1 (MuRF1), atrogin-1, and histone deacetylase 4 (HDAC4I) [75,79,80]. Our results show that miR-29a/b/c are significantly upregulated in LDM from IUGR fetuses and are negatively correlated and can potentially target 92 downregulated genes (Figure 2, Table S2). The miR-29 target genes enriched important biological pathways including bone morphogenesis, placenta blood vessel development, ADP metabolic process, and ATP generation from ADP. Placental insufficiency is one of the leading causes for the development of IUGR [6]. We suggest that dysregulation of miR-29 and their target genes can lead to serious impairments in skeletal muscle growth and placental development, contributing to the pathogenesis of IUGR.

Other than the regulation of key biological processes, downregulated target genes of upregulated miRNAs in LDM from IUGR fetuses also enriched important KEGG pathways including the calcium signaling pathway, thyroid hormone signaling pathway, glycolysis/gluconeogenesis, and Hippo signaling pathway (Figure 6). Calcium signaling plays a key role during different stages of prenatal muscle development as well as during postnatal maintenance and regeneration of skeletal muscles [81]. During the early developmental stages, calcium transients of long duration (80 s) occur only during a small time window during fetal development [81]. An artificial increase in the length of calcium transients negatively affects muscle development [82], indicating the importance of precise calcium signaling during skeletal muscle development. According to our results, 13 genes involved in calcium signaling are downregulated in LDM from IUGR fetuses and are potential targets of upregulated miRNAs. The hippo signaling pathway controls the development and size of multiple tissues and organs in the body, and is a critical regulator of skeletal muscle mass $[83,84]$. When active, the Hippo signaling pathway inhibits cell migration and proliferation by inhibiting proliferation-associated genes such as TEA domain transcription factor 4 (TEAD4), fibroblast growth factor $(F G F)$, and baculoviral IAP repeat containing 5 (BIRC5) [85]. Interestingly, these genes are downregulated in LDM from IUGR fetuses, indicating increased activity of Hippo signaling pathways. Moreover, transforming growth factor beta $(T G F B)$ targets the Hippo signaling pathway to stimulate cell invasion and proliferation [86]. Our data shows that TGFB is significantly reduced in LDM from IUGR fetuses, which can lead to the activation of the Hippo signaling pathway. We suggest 
that the increased activity of the Hippo signaling pathway in skeletal muscles from IUGR fetuses could be contributing to reduced muscle growth in these fetuses.

Pathophysiology of IUGR is not limited to only reduced prenatal fetal growth, but can also lead to long term problems after birth including insulin resistance, metabolic syndrome, and type 2 diabetes [87]. Hence, IUGR predisposes the fetus to development of postnatal or adult heath disorders $[88,89]$, a phenomenon first introduced as Barker's hypothesis [90]. Interestingly, the downregulated genes in LDM from IUGR fetuses enriched well-known metabolism-associated pathways including thyroid hormone signaling pathway, parathyroid hormone synthesis, secretion and action, and glycolysis/gluconeogenesis (Figure 6). In this context, the enrichment analysis of upregulated genes showed more interesting results. Upregulated target genes of downregulated miRNAs (Table S3) enriched important metabolic pathways. The majority of the top 10 biological processes enriched by upregulated genes are associated with metabolism, including the macromolecule metabolic process, primary metabolic process, nitrogen compound metabolic process, and nucleic acid metabolic process (Figure 7A). Moreover, upregulated genes in LDM from IUGR fetuses also enriched the thyroid hormone signaling pathway (Figure 7B). Thyroid hormones are critical for normal fetal growth and metabolism and facilitate the terminal differentiation of different fetal tissues [91]. They regulate important metabolic pathways such as glucose metabolism, lipolysis, and regulation of body weight [92]. Different studies have described the role of cellular metabolism in skeletal muscle development and regeneration [93-95]. Additionally, the most enriched pathway by upregulated genes is ubiquitin-mediated proteolysis (Figure 7B). Bachiller et al. recently reviewed ubiquitin-mediated proteolysis in several skeletal muscle disorders including muscle atrophy, defective growth of neuromuscular junction, nemaline myopathy, and reduced proliferation, and differentiation of myoblasts [96]. We suggest that dysregulation of metabolic pathways and upregulation of the ubiquitin pathway in skeletal muscles is not only associated with the pathophysiology of IUGR, but can also cause severe complications after birth and contribute toward increased morbidity and mortality in IUGR-affected piglets.

Due to their ability to target a wide range of genes and their involvement in the regulation of diverse biological processes, miRNAs have been under an immense focus to be used as diagnostic and therapeutic targets. Based on the existing evidence of trafficking of miRNAs through circulation and export of placental and fetal miRNAs to maternal circulation [97-100], we suggest that the dysregulated miRNAs in fetal skeletal muscles can be exported to other tissues and affect multiple organ systems in both the mother and the fetus. If detected in maternal circulation, the dysregulated miRNAs in fetal skeletal muscle can potentially serve as biomarkers of IUGR in pigs. However, further studies are needed to understand the roles of individual miRNAs in the pathogenesis of IUGR and to explore the possibility of the transport and identification of fetal skeletal muscle-originated miRNAs in maternal circulation.

Supplementary Materials: The following are available online at https:/ / www.mdpi.com/article/10 .3390/cells10051007/s1: Table S1: qPCR primers, Table S2: Upregulated miRNAs and target genes, Table S3: Downregulated miRNAs and target genes, Table S4: BPs enriched by downregulated genes, Table S5: KEGG pathways enriched by downregulated genes, Table S6: Novel miRNAmRNA networks

Author Contributions: Conceptualization: A.A., E.M., K.W. and S.P.; methodology: S.P. and A.A.; software: S.P., A.A. and F.H.; formal analysis: S.P. and A.A.; investigation: E.M., S.P. and A.A.; resources, E.M. and K.W.; writing—original draft preparation: A.A.; writing—review and editing: S.P., F.H., E.M., X.L. and K.W.; supervision: S.P.; project administration: S.P. All authors have read and agreed to the published version of the manuscript.

Funding: This research received no external funding.

Institutional Review Board Statement: Animal care and tissue collection procedures were approved by the Animal Care Committee of the Leibniz Institute for Farm Animal Biology and carried out in accordance with the approved guidelines for safeguarding good scientific practice at the institutions 
in the Leibniz Association and the measures were taken to minimize pain and discomfort and accord with the guidelines laid down by the European Communities Council Directive of 24 November 1986 (86/609/EEC). For this study, the animals were used for meat production and underwent no experimental treatment, diagnostic sampling, or any other intervention before killing therefore not requiring specific ethical approval. Animal handling as well as the killing was in accordance with applicable laws, relevant guidelines, and provisions for ethical regulations.

Informed Consent Statement: Not applicable.

Data Availability Statement: The expression data are available in the Gene Expression Omnibus public repository with the GEO accession number GSE169093.

Acknowledgments: The authors thank Nicole Gentz, Annette Jugert, and Joana Bittner for excellent technical assistance.

Conflicts of Interest: The authors declare no conflict of interest.

\section{References}

1. Chen, Z.; Ye, S.; Teng, J.; Diao, S.; Yuan, X.; Chen, Z.; Zhang, H.; Li, J.; Zhang, Z. Genome-wide association studies for the number of animals born alive and dead in duroc pigs. Theriogenology 2019, 139, 36-42. [CrossRef]

2. Camargo, E.G.; Marques, D.B.D.; De Figueiredo, E.A.P.; Silva, F.F.E.; Lopes, P.S. Genetic study of litter size and litter uniformity in Landrace pigs. Rev. Bras. Zootec. 2020, 49, 49. [CrossRef]

3. Wang, W.; DeGroote, J.; Van Ginneken, C.; Van Poucke, M.; Vergauwen, H.; Dam, T.M.T.; Vanrompay, D.; Peelman, L.J.; De Smet, S.; Michiels, J. Intrauterine growth restriction in neonatal piglets affects small intestinal mucosal permeability and mRNA expression of redox-sensitive genes. FASEB J. 2015, 30, 863-873. [CrossRef]

4. Wu, G.; Bazer, F.W.; Wallace, J.M.; Spencer, T.E. Board-Invited Review: Intrauterine growth retardation: Implications for the animal sciences. J. Anim. Sci. 2006, 84, 2316-2337. [CrossRef] [PubMed]

5. D'Incà, R.; Che, L.; Thymann, T.; Sangild, P.; Le Huërou-Luron, I. Intrauterine growth restriction reduces intestinal structure and modifies the response to colostrum in preterm and term piglets. Livest. Sci. 2010, 133, 20-22. [CrossRef]

6. Novac, M.V.; Niculescu, M.; Manolea, M.M.; Dijmărescu, A.L.; Iliescu, D.G.; Novac, M.B.; Rotaru, L.T.; Stoenescu, M.F.; Tabacu, M.C.; Tudorache, Ş.; et al. Placental findings in pregnancies complicated with IUGR-Histopathological and immunohistochemical analysis. Rom. J. Morphol. Embryol. Rev. Roum. Morphol. Embryol. 2018, 59, 715-720.

7. Zeve, D.; Regelmann, M.O.; Holzman, I.R.; Rapaport, R. Small at Birth, but How Small? The Definition of SGA Revisited. Horm. Res. Paediatr. 2016, 86, 357-360. [CrossRef] [PubMed]

8. Wang, J.; Feng, C.; Liu, T.; Shi, M.; Wu, G.; Bazer, F.W. Physiological alterations associated with intrauterine growth restriction in fetal pigs: Causes and insights for nutritional optimization. Mol. Reprod. Dev. 2017, 84, 897-904. [CrossRef]

9. Krueger, R.; Derno, M.; Goers, S.; Metzler-Zebeli, B.U.; Nuernberg, G.; Martens, K.; Pfuhl, R.; Nebendahl, C.; Zeyner, A.; Hammon, H.M.; et al. Higher body fatness in intrauterine growth retarded juvenile pigs is associated with lower fat and higher carbohydrate oxidation during ad libitum and restricted feeding. Eur. J. Nutr. 2014, 53, 583-597. [CrossRef]

10. Nissen, P.M.; Oksbjerg, N. Birth weight and postnatal dietary protein level affect performance, muscle metabolism and meat quality in pigs. Animal 2011, 5, 1382-1389. [CrossRef]

11. Wang, T.; Liu, C.; Feng, C.; Wang, X.; Lin, G.; Zhu, Y.; Yin, J.; Li, D.; Wang, J. IUGR alters muscle fiber development and proteome in fetal pigs. Front. Biosci. 2013, 18, 598-607. [CrossRef]

12. Snyder, W.; Cook, M.; Nasset, E.; Karhausen, L.; Howells, G.P.; Tipton, I. Report of the Task Group on Reference Man; Pergamon: Oxford, UK, 1975; Volume 23.

13. Năstase, L.; Cretoiu, D.; Stoicescu, S.M. Skeletal muscle damage in intrauterine growth restriction. Adv. Exp. Med. Biol. 2018, 1088, 93-106. [CrossRef]

14. Soto, S.M.; Blake, A.C.; Wesolowski, S.R.; Rozance, P.J.; Barthels, K.B.; Gao, B.; Hetrick, B.; McCurdy, C.E.; Garza, N.G.; Hay, W.W., Jr. Myoblast replication is reduced in the IUGR fetus despite maintained proliferative capacity in vitro. J. Endocrinol. 2017, 232, 475. [CrossRef]

15. Zhang, L.; Zhou, X.; Michal, J.J.; Ding, B.; Li, R.; Jiang, Z. Genome Wide Screening of Candidate Genes for Improving Piglet Birth Weight Using High and Low Estimated Breeding Value Populations. Int. J. Biol. Sci. 2014, 10, 236-244. [CrossRef] [PubMed]

16. Rehfeldt, C.; Kuhn, G. Consequences of birth weight for postnatal growth performance and carcass quality in pigs as related to myogenesis. J. Anim. Sci. 2006, 84, E113-E123. [CrossRef] [PubMed]

17. Ashmore, C.R.; Addis, P.B.; Doerr, L. Development of Muscle Fibers in the Fetal Pig. J. Anim. Sci. 1973, 36, 1088-1093. [CrossRef]

18. Picard, B.; Lefaucheur, L.; Berri, C.; Duclos, M.J. Muscle fibre ontogenesis in farm animal species. Reprod. Nutr. Dev. 2002, 42, 415-431. [CrossRef]

19. Davoli, R.; Braglia, S.; Russo, V.; Varona, L.; Te Pas, M.F.W. Expression profiling of functional genes in prenatal skeletal muscle tissue in Duroc and Pietrain pigs. J. Anim. Breed. Genet. 2010, 128, 15-27. [CrossRef]

20. Miersch, C.; Stange, K.; Hering, S.; Kolisek, M.; Viergutz, T.; Röntgen, M. Molecular and functional heterogeneity of early postnatal porcine satellite cell populations is associated with bioenergetic profile. Sci. Rep. 2017, 7, srep45052. [CrossRef] 
21. Bérard, J.; Kalbe, C.; Lösel, D.; Tuchscherer, A.; Rehfeldt, C. Potential sources of early-postnatal increase in myofibre number in pig skeletal muscle. Histochem. Cell Biol. 2011, 136, 217-225. [CrossRef] [PubMed]

22. Sambasivan, R.; Tajbakhsh, S. Skeletal muscle stem cell birth and properties. Semin. Cell Dev. Biol. 2007, 18, 870-882. [CrossRef] [PubMed]

23. Zhao, Y.; Li, J.; Liu, H.; Xi, Y.; Xue, M.; Liu, W.; Zhuang, Z.; Lei, M. Dynamic transcriptome profiles of skeletal muscle tissue across 11 developmental stages for both Tongcheng and Yorkshire pigs. BMC Genom. 2015, 16, 377. [CrossRef] [PubMed]

24. Lefaucheur, L. Myofibre typing and its relationships to growth performance and meat quality. Arch. Anim. Breed. 2006, 49, 4-17.

25. Stickland, N.C.; Handel, S.E. The numbers and types of muscle fibres in large and small breeds of pigs. J. Anat. 1986, 147, 181-189.

26. Brown, L.D. Endocrine regulation of fetal skeletal muscle growth: Impact on future metabolic health. J. Endocrinol. 2014, 221, R13-R29. [CrossRef]

27. Alberti, C.; Cochella, L. A framework for understanding the roles of miRNAs in animal development. Development 2017, 144, 2548-2559. [CrossRef]

28. O'Brien, J.; Hayder, H.; Zayed, Y.; Peng, C. Overview of MicroRNA Biogenesis, Mechanisms of Actions, and Circulation. Front. Endocrinol. 2018, 9, 402. [CrossRef]

29. Ali, A.; Stenglein, M.D.; Spencer, T.E.; Bouma, G.J.; Anthony, R.V.; Winger, Q.A. Trophectoderm-Specific Knockdown of LIN28 Decreases Expression of Genes Necessary for Cell Proliferation and Reduces Elongation of Sheep Conceptus. Int. J. Mol. Sci. 2020, 21, 2549. [CrossRef]

30. Ali, A.; Bouma, G.J.; Anthony, R.V.; Winger, Q.A. The Role of LIN28-let-7-ARID3B Pathway in Placental Development. Int. J. Mol. Sci. 2020, 21, 3637. [CrossRef]

31. Mir, B.A.; Reyer, H.; Komolka, K.; Ponsuksili, S.; Kühn, C.; Maak, S. Differentially expressed miRNA-gene targets related to intramuscular fat in musculus longissimus dorsi of Charolais $\times$ Holstein F2-crossbred bulls. Genes 2020, 11, 700. [CrossRef] [PubMed]

32. Bartel, D.P. MicroRNAs: Target Recognition and Regulatory Functions. Cell 2009, 136, 215-233. [CrossRef]

33. Siengdee, P.; Trakooljul, N.; Muràni, E.; Brand, B.; Schwerin, M.; Wimmers, K.; Ponsuksili, S. Pre- and post-natal muscle microRNA expression profiles of two pig breeds differing in muscularity. Gene 2015, 561, 190-198. [CrossRef] [PubMed]

34. Pereira, A.; Felicioni, F.; Caldeira-Brant, A.; Magnabosco, D.; Bortolozzo, F.; Tsoi, S.; Dyck, M.; Dixon, W.; Martinelli, P.; Jorge, E. Postnatal development of skeletal muscle in IUGR pigs: Morphofunctional phenotype and molecular mechanisms. J. Anat. 2020, 236, 840-853. [CrossRef]

35. Zhang, X.; Cai, S.; Chen, L.; Yuan, R.; Nie, Y.; Ding, S.; Fang, Y.; Zhu, Q.; Chen, K.; Wei, H.; et al. Integrated miRNA-mRNA transcriptomic analysis reveals epigenetic-mediated embryonic muscle growth differences between Wuzhishan and Landrace pigs. J. Anim. Sci. 2019, 97, 1967-1978. [CrossRef]

36. Ayuso, M.; Fernández, A.; Núñez, Y.; Benítez, R.; Isabel, B.; Fernández, A.I.; Rey, A.I.; González-Bulnes, A.; Medrano, J.F.; Cánovas, Á.; et al. Developmental Stage, Muscle and Genetic Type Modify Muscle Transcriptome in Pigs: Effects on Gene Expression and Regulatory Factors Involved in Growth and Metabolism. PLoS ONE 2016, 11, e0167858. [CrossRef]

37. Ropka-Molik, K.; Pawlina-Tyszko, K.; Żukowski, K.; Piórkowska, K.; Żak, G.; Gurgul, A.; Derebecka, N.; Wesoły, J. Examining the Genetic Background of Porcine Muscle Growth and Development Based on Transcriptome and miRNAome Data. Int. J. Mol. Sci. 2018, 19, 1208. [CrossRef]

38. Qin, L.; Chen, Y.; Liu, X.; Ye, S.; Yu, K.; Huang, Z.; Yu, J.; Zhou, X.; Chen, H.; Mo, D. Integrative Analysis of Porcine microRNAome during Skeletal Muscle Development. PLoS ONE 2013, 8, e72418. [CrossRef]

39. Muráni, E.; Murániová, M.; Ponsuksili, S.; Schellander, K.; Wimmers, K. Identification of genes differentially expressed during prenatal development of skeletal muscle in two pig breeds differing in muscularity. BMC Dev. Biol. 2007, 7, 109. [CrossRef]

40. Li, L.; Shi, J.-Y.; Zhu, G.-Q.; Shi, B. MiR-17-92 cluster regulates cell proliferation and collagen synthesis by targeting TGFB pathway in mouse palatal mesenchymal cells. J. Cell. Biochem. 2011, 113, 1235-1244. [CrossRef]

41. Chen, Z.; Pan, X.; Sheng, Z.; Yan, G.; Chen, L.; Ma, G. miR-17 regulates the proliferation and apoptosis of endothelial cells in coronary heart disease via targeting insulin-like-growth factor. Pathol. Res. Pract. 2019, 215, 152512. [CrossRef]

42. Siengdee, P.; Trakooljul, N.; Murani, E.; Schwerin, M.; Wimmers, K.; Ponsuksili, S. Transcriptional profiling and miRNAdependent regulatory network analysis of longissimus dorsi muscle during prenatal and adult stages in two distinct pig breeds. Anim. Genet. 2013, 44, 398-407. [CrossRef] [PubMed]

43. Benjamini, Y.; Hochberg, Y. Controlling the False Discovery Rate-A Practical and Powerful Approach to Multiple Testing. J. R. Stat. Soc. Ser. B Methodol. 1995, 57, 289-300. [CrossRef]

44. Rehmsmeier, M.; Steffen, P.; Höchsmann, M.; Giegerich, R. Fast and effective prediction of microRNA/target duplexes. RNA 2004, 10, 1507-1517. [CrossRef] [PubMed]

45. Krüger, J.; Rehmsmeier, M. RNAhybrid: MicroRNA target prediction easy, fast and flexible. Nucleic Acids Res. 2006, 34, W451-W454. [CrossRef]

46. Fantini, D. EasyPubMed: Search and Retrieve Scientific Publication Records from PubMed. 2019. Available online: https: //www.data-pulse.com/dev_site/easypubmed/ (accessed on 1 April 2021).

47. Gao, J.; Tarcea, V.G.; Karnovsky, A.; Mirel, B.R.; Weymouth, T.E.; Beecher, C.W.; Cavalcoli, J.D.; Athey, B.D.; Omenn, G.S.; Burant, C.F.; et al. Metscape: A Cytoscape plug-in for visualizing and interpreting metabolomic data in the context of human metabolic networks. Bioinformatics 2010, 26, 971-973. [CrossRef] 
48. Bindea, G.; Galon, J.; Mlecnik, B. CluePedia Cytoscape plugin: Pathway insights using integrated experimental and in silico data. Bioinformatics 2013, 29, 661-663. [CrossRef]

49. Bindea, G.; Mlecnik, B.; Hackl, H.; Charoentong, P.; Tosolini, M.; Kirilovsky, A.; Fridman, W.-H.; Pagès, F.; Trajanoski, Z.; Galon, J. ClueGO: A Cytoscape plug-in to decipher functionally grouped gene ontology and pathway annotation networks. Bioinformatics 2009, 25, 1091-1093. [CrossRef]

50. Shannon, P.; Markiel, A.; Ozier, O.; Baliga, N.S.; Wang, J.T.; Ramage, D.; Amin, N.; Schwikowski, B.; Ideker, T. Cytoscape: A software environment for integrated models of biomolecular interaction networks. Genome Res. 2003, 13, 2498-2504. [CrossRef]

51. Wang, J.; Vasaikar, S.V.; Shi, Z.; Greer, M.; Zhang, B. WebGestalt 2017: A more comprehensive, powerful, flexible and interactive gene set enrichment analysis toolkit. Nucleic Acids Res. 2017, 45, W130-W137. [CrossRef] [PubMed]

52. Liao, Y.; Wang, J.; Jaehnig, E.J.; Shi, Z.; Zhang, B. WebGestalt 2019: Gene set analysis toolkit with revamped UIs and APIs. Nucleic Acids Res. 2019, 47, W199-W205. [CrossRef] [PubMed]

53. Warnes, G.R.; Bolker, B.; Bonebakker, L.; Gentleman, R.; Huber, W.; Liaw, A.; Lumley, T.; Maechler, M.; Magnusson, A.; Moeller, S. gplots: Various R programming tools for plotting data. R Package Version 2009, $2,1$.

54. Luo, H.; Lv, W.; Tong, Q.; Jin, J.; Xu, Z.; Zuo, B. Functional Non-coding RNA During Embryonic Myogenesis and Postnatal Muscle Development and Disease. Front. Cell Dev. Biol. 2021, 9, 49. [CrossRef]

55. Ali, A.; Anthony, R.V.; Bouma, G.J.; Winger, Q.A. LIN28-let-7 axis regulates genes in immortalized human trophoblast cells by targeting the ARID3B-complex. FASEB J. 2019, 33, 12348-12363. [CrossRef]

56. Gebremedhn, S.; Ali, A.; Hossain, M.; Hoelker, M.; Salilew-Wondim, D.; Anthony, R.V.; Tesfaye, D. MicroRNA-Mediated Gene Regulatory Mechanisms in Mammalian Female Reproductive Health. Int. J. Mol. Sci. 2021, 22, 938. [CrossRef]

57. Ali, A.; Hadlich, F.; Abbas, M.W.; Iqbal, M.A.; Tesfaye, D.; Bouma, G.J.; Winger, Q.A.; Ponsuksili, S. MicroRNA-mRNA Networks in Pregnancy Complications: A Comprehensive Downstream Analysis of Potential Biomarkers. Int. J. Mol. Sci. 2021, $22,2313$. [CrossRef] [PubMed]

58. Hu, X.-Q.; Zhang, L. MicroRNAs in Uteroplacental Vascular Dysfunction. Cells 2019, 8, 1344. [CrossRef] [PubMed]

59. Zheng, Y.; Kong, J.; Li, Q.; Wang, Y.; Li, J. Role of miRNAs in skeletal muscle aging. Clin. Interv. Aging 2018, 13, 2407-2419. [CrossRef]

60. Fulzele, S.; Mendhe, B.; Khayrullin, A.; Johnson, M.; Kaiser, H.; Liu, Y.; Isales, C.M.; Hamrick, M.W. Muscle-derived miR-34a increases with age in circulating extracellular vesicles and induces senescence of bone marrow stem cells. Aging 2019, 11, 1791-1803. [CrossRef]

61. Ge, X.; Sathiakumar, D.; Lua, B.J.G.; Kukreti, H.; Lee, M.; McFarlane, C. Myostatin signals through miR-34a to regulate Fndc5 expression and browning of white adipocytes. Int. J. Obes. 2016, 41, 137-148. [CrossRef]

62. Bavelloni, A.; Ramazzotti, G.; Poli, A.; Piazzi, M.; Focaccia, E.; Blalock, W.; Faenza, I. MiRNA-210: A Current Overview. Anticancer Res. 2017, 37, 6511-6521. [CrossRef] [PubMed]

63. Cicchillitti, L.; Di Stefano, V.; Isaia, E.; Crimaldi, L.; Fasanaro, P.; Ambrosino, V.; Antonini, A.; Capogrossi, M.C.; Gaetano, C.; Piaggio, G.; et al. Hypoxia-inducible Factor 1- $\alpha$ Induces miR-210 in Normoxic Differentiating Myoblasts. J. Biol. Chem. 2012, 287, 44761-44771. [CrossRef]

64. Liu, X.; Trakooljul, N.; Hadlich, F.; Muráni, E.; Wimmers, K.; Ponsuksili, S. MicroRNA-mRNA regulatory networking fine-tunes the porcine muscle fiber type, muscular mitochondrial respiratory and metabolic enzyme activities. BMC Genom. 2016, 17, 1-14. [CrossRef] [PubMed]

65. Sampath, S.C.; Sampath, S.C.; Millay, D.P. Myoblast fusion confusion: The resolution begins. Skelet. Muscle 2018, 8, 1-10. [CrossRef] [PubMed]

66. Hindi, S.M.; Shin, J.; Gallot, Y.S.; Straughn, A.R.; Simionescu-Bankston, A.; Hindi, L.; Xiong, G.; Friedland, R.P.; Kumar, A. MyD88 promotes myoblast fusion in a cell-autonomous manner. Nat. Commun. 2017, 8, 1624. [CrossRef] [PubMed]

67. Doherty, K.R.; Cave, A.; Davis, D.B.; Delmonte, A.J.; Posey, A.; Earley, J.U.; Hadhazy, M.; McNally, E.M. Normal myoblast fusion requires myoferlin. Development 2005, 132, 5565-5575. [CrossRef]

68. Latroche, C.; Weiss-Gayet, M.; Muller, L.; Gitiaux, C.; Leblanc, P.; Liot, S.; Ben-Larbi, S.; Abou-Khalil, R.; Verger, N.; Bardot, P.; et al. Coupling between Myogenesis and Angiogenesis during Skeletal Muscle Regeneration Is Stimulated by Restorative Macrophages. Stem Cell Rep. 2017, 9, 2018-2033. [CrossRef]

69. Ranjbar, K.; Fayazi, B. Vascularisation of Skeletal Muscle. In Muscle Cells-Recent Advances and Future Perspectives; IntechOpen: London, UK, 2020.

70. Feng, Y.; Niu, L.; Wei, W.; Zhang, W.; Li, X.; Cao, J.; Zhao, S. A feedback circuit between miR-133 and the ERK1/2 pathway involving an exquisite mechanism for regulating myoblast proliferation and differentiation. Cell Death Dis. 2013, 4, e934. [CrossRef]

71. Horak, M.; Novak, J.; Bienertova-Vasku, J. Muscle-specific microRNAs in skeletal muscle development. Dev. Biol. 2016, 410, 1-13. [CrossRef]

72. Deng, Z.; Chen, J.-F.; Wang, D.-Z. Transgenic overexpression of miR-133a in skeletal muscle. BMC Musculoskelet. Disord. 2011, 12, 115. [CrossRef]

73. Koutsoulidou, A.; Mastroyiannopoulos, N.P.; Furling, D.; Uney, J.B.; Phylactou, L.A. Expression of miR-1, miR-133a, miR-133b and miR-206 increases during development of human skeletal muscle. BMC Dev. Biol. 2011, 11, 34. [CrossRef] 
74. Yu, H.; Lu, Y.; Li, Z.; Wang, Q. microRNA-133: Expression, Function and Therapeutic Potential in Muscle Diseases and Cancer. Curr. Drug Targets 2014, 15, 817-828. [CrossRef]

75. Wei, W.; He, H.B.; Zhang, W.Y.; Zhang, H.X.; Bai, J.B.; Liu, H.Z.; Cao, J.H.; Chang, K.C.; Li, X.Y.; Zhao, S.H. miR-29 targets Akt3 to reduce proliferation and facilitate differentiation of myoblasts in skeletal muscle development. Cell Death Dis. 2013, 4, e668. [CrossRef]

76. Chen, L.; Bai, J.; Li, Y. miR-29 mediates exercise-induced skeletal muscle angiogenesis by targeting VEGFA, COL4A1 and COL4A2 via the PI3K/Akt signaling pathway. Mol. Med. Rep. 2020, 22, 661-670. [CrossRef]

77. Li, Z.; Hassan, M.Q.; Jafferji, M.; Aqeilan, R.I.; Garzon, R.; Croce, C.M.; van Wijnen, A.J.; Stein, J.L.; Stein, G.S.; Lian, J.B. Biological Functions of miR-29b Contribute to Positive Regulation of Osteoblast Differentiation. J. Biol. Chem. 2009, 284, 15676-15684. [CrossRef]

78. Kapinas, K.; Kessler, C.; Ricks, T.; Gronowicz, G.; Delany, A.M. miR-29 Modulates Wnt Signaling in Human Osteoblasts through a Positive Feedback Loop. J. Biol. Chem. 2010, 285, 25221-25231. [CrossRef] [PubMed]

79. Zhou, L.; Wang, L.; Lu, L.; Jiang, P.; Sun, H.; Wang, H. A Novel Target of MicroRNA-29, Ring1 and YY1-binding Protein (Rybp), Negatively Regulates Skeletal Myogenesis. J. Biol. Chem. 2012, 287, 25255-25265. [CrossRef]

80. Silva, W.J.; Graça, F.A.; Cruz, A.; Silvestre, J.G.; Labeit, S.; Miyabara, E.H.; Yan, C.Y.I.; Wang, D.Z.; Moriscot, A.S. miR-29c improves skeletal muscle mass and function throughout myocyte proliferation and differentiation and by repressing atrophy-related genes. Acta Physiol. 2019, 226, e13278. [CrossRef] [PubMed]

81. Tu, M.K.; Levin, J.B.; Hamilton, A.M.; Borodinsky, L.N. Calcium signaling in skeletal muscle development, maintenance and regeneration. Cell Calcium 2016, 59, 91-97. [CrossRef] [PubMed]

82. Campbell, N.R.; Podugu, S.P.; Ferrari, M.B.; Ferrari, T.M. Spatiotemporal characterization of short versus long duration calcium transients in embryonic muscle and their role in myofibrillogenesis. Dev. Biol. 2006, 292, 253-264. [CrossRef] [PubMed]

83. Watt, K.I.; Turner, B.J.; Hagg, A.; Zhang, X.; Davey, J.R.; Qian, H.; Beyer, C.; Winbanks, C.E.; Harvey, K.F.; Gregorevic, P. The Hippo pathway effector YAP is a critical regulator of skeletal muscle fibre size. Nat. Commun. 2015, 6, 1-13. [CrossRef]

84. Watt, K.I.; Goodman, C.A.; Hornberger, T.A.; Gregorevic, P. The Hippo Signaling Pathway in the Regulation of Skeletal Muscle Mass and Function. Exerc. Sport Sci. Rev. 2018, 46, 92-96. [CrossRef]

85. Boopathy, G.T.K.; Hong, W. Role of Hippo Pathway-YAP/TAZ Signaling in Angiogenesis. Front. Cell Dev. Biol. 2019, 7, 49. [CrossRef]

86. Pefani, D.-E.; Pankova, D.; Abraham, A.G.; Grawenda, A.M.; Vlahov, N.; Scrace, S.; O'Neill, E. TGF- $\beta$ Targets the Hippo Pathway Scaffold RASSF1A to Facilitate YAP/SMAD2 Nuclear Translocation. Mol. Cell 2016, 63, 156-166. [CrossRef]

87. Darendeliler, F. IUGR: Genetic influences, metabolic problems, environmental associations/triggers, current and future management. Best Pract. Res. Clin. Endocrinol. Metab. 2019, 33, 101260. [CrossRef]

88. Mierzynski, R.; Dluski, D.; Darmochwal-Kolarz, D.; Poniedziałek-Czajkowska, E.; Leszczynska-Gorzelak, B.; Kimber-Trojnar, Z.; Oleszczuk, J.; Bentham Science Publisher Agnieszka-Wankowicz. Intrauterine Growth Retardation as a Risk Factor of Postnatal Metabolic Disorders. Curr. Pharm. Biotechnol. 2016, 17, 587-596. [CrossRef]

89. Valsamakis, G.; Kanaka-Gantenbein, C.; Malamitsi-Puchner, A.; Mastorakos, G. Causes of intrauterine growth restriction and the postnatal development of the metabolic syndrome. Ann. N. Y. Acad. Sci. 2006, 1092, 138-147. [CrossRef] [PubMed]

90. Barker, D.J.P. Fetal origins of coronary heart disease. BMJ 1995, 311, 171-174. [CrossRef] [PubMed]

91. Forhead, A.J.; Fowden, A.L. Thyroid hormones in fetal growth and prepartum maturation. J. Endocrinol. 2014, 221, R87-R103. [CrossRef]

92. Liu, Y.-Y.; Brent, G.A. Thyroid hormone crosstalk with nuclear receptor signaling in metabolic regulation. Trends Endocrinol. Metab. 2010, 21, 166-173. [CrossRef]

93. Koopman, R.; Ly, C.H.; Ryall, J.G. A metabolic link to skeletal muscle wasting and regeneration. Front. Physiol. 2014, 5, 32. [CrossRef]

94. Ryall, J.G. Metabolic reprogramming as a novel regulator of skeletal muscle development and regeneration. FEBS J. 2013, 280, 4004-4013. [CrossRef]

95. Gloux, A.; Le Roy, N.; Brionne, A.; Bonin, E.; Juanchich, A.; Benzoni, G.; Piketty, M.L.; Prié, D.; Nys, Y.; Gautron, J.; et al. Candidate genes of the transcellular and paracellular calcium absorption pathways in the small intestine of laying hens. Poult. Sci. 2019, 98, 6005-6018. [CrossRef] [PubMed]

96. Bachiller, S.; Alonso-Bellido, I.M.; Real, L.M.; Pérez-Villegas, E.M.; Venero, J.L.; Deierborg, T.; Armengol, J.Á.; Ruiz, R. The Ubiquitin Proteasome System in Neuromuscular Disorders: Moving Beyond Movement. Int. J. Mol. Sci. 2020, 21, 6429. [CrossRef]

97. Luo, S.-S.; Ishibashi, O.; Ishikawa, G.; Ishikawa, T.; Katayama, A.; Mishima, T.; Takizawa, T.; Shigihara, T.; Goto, T.; Izumi, A.; et al. Human Villous Trophoblasts Express and Secrete Placenta-Specific MicroRNAs into Maternal Circulation via Exosomes. Biol. Reprod. 2009, 81, 717-729. [CrossRef] [PubMed]

98. Miura, K.; Miura, S.; Yamasaki, K.; Higashijima, A.; Kinoshita, A.; Yoshiura, K.-I.; Masuzaki, H. Identification of PregnancyAssociated MicroRNAs in Maternal Plasma. Clin. Chem. 2010, 56, 1767-1771. [CrossRef]

99. Cai, M.; Kolluru, G.K.; Ahmed, A. Small Molecule, Big Prospects: MicroRNA in Pregnancy and Its Complications. J. Pregnancy 2017, 2017, 1-15. [CrossRef]

100. Bär, C.; Thum, T.; De Gonzalo-Calvo, D. Circulating miRNAs as mediators in cell-to-cell communication. Epigenomics 2019, 11, 111-113. [CrossRef] 